\title{
A Decade of Boon or Burden: What Has the CHIP Ever Done for Cellular Protein Quality Control Mechanism Implicated in Neurodegeneration and Aging?
}

\author{
Vibhuti Joshi ${ }^{1}$, Ayeman Amanullah ${ }^{1}$, Arun Upadhyay ${ }^{1}$, Ribhav Mishra ${ }^{1}$, Amit Kumar ${ }^{2}$ \\ and Amit Mishra ${ }^{1 *}$
}

${ }^{1}$ Cellular and Molecular Neurobiology Unit, Indian Institute of Technology Jodhpur, Rajasthan, India, ${ }^{2}$ Centre for Biosciences and Biomedical Engineering, Indian Institute of Technology Indore, Madhya Pradesh, India

Cells regularly synthesize new proteins to replace old and abnormal proteins for normal cellular functions. Two significant protein quality control pathways inside the cellular milieu are ubiquitin proteasome system (UPS) and autophagy. Autophagy is known for bulk clearance of cytoplasmic aggregated proteins, whereas the specificity of protein degradation by UPS comes from E3 ubiquitin ligases. Few E3 ubiquitin ligases, like C-terminus of Hsc70-interacting protein (CHIP) not only take part in protein quality control pathways, but also plays a key regulatory role in other cellular processes like signaling, development, DNA damage repair, immunity and aging.

\section{OPEN ACCESS}

Edited by:

Angelo Poletti,

Università degli Studi di Milano, Italy

Reviewed by:

Clare Wilhelm,

VA Portland Health Care System,

USA

Andrew P. Lieberman University of Michigan, USA

*Correspondence: Amit Mishra amit@itij.ac.in

Received: 04 July 2016 Accepted: 20 September 2016 Published: 04 October 2016

Citation: Joshi V, Amanullah A, Upadhyay A, Mishra R, Kumar A and Mishra A (2016) A Decade of Boon or Burden:

What Has the CHIP Ever Done for Cellular Protein Quality Contro Mechanism Implicated in Neurodegeneration and Aging? Front. Mol. Neurosci. 9:93. doi: 10.3389/fnmol.2016.00093
Abbreviations: AhR, aryl hydrocarbon receptor; AIF, apoptosis-inducing factor; Akt, AKR/J thyoma protein kinase; ALS, amyotrophic lateral sclerosis; APC, anaphase promoting complex; APP, amyloid precursor protein; AR, androgen receptor; ASK1, apoptosis signal-regulating kinase 1; AXL, receptor tyrosine kinase AXL; BAG, B-cell lymphoma-2 (BCL-2)-associated athanogene; BCR- ABL, break point cluster abelson murine leukemia viral oncogene; BMP, bone morphogenetic protein; CAD, caspase recruitment domain; CAP, chaperone-assisted proteasomal degradation; CARMA1, CAD containing membrane-associated guanylate kinase 1; CASA, chaperone-assisted selective autophagy; CDK5, cyclindependent kinase 5; CFTR, cystic-fibrosis transmembrane-conductance regulator; CHIP, C-terminus of Hsc70-interacting protein; CMA, chaperone-mediated autophagy; c-myc, cellular myelocytomatosis viral oncogene homolog; CtBP2, Cterminal binding protein 2; CYP3A4, cytochrome P450 isoform 3A4; CytP450, cytochrome P450; DLK, dual leucine zipperbearing kinase; DNA Lig III, DNA ligase III; DNA pol B, DNA polymerase B; DUB, deubiquitylating enzyme; EGFR, epidermal growth factor receptor; eIF4E, eukaryotic translation initiation factor 4E; eIF5a, eukaryotic translation initiation factor 5a; ER, estrogen receptor; ErbB2, erythroblastic leukemia viral oncogene homolog 2; ERK, extracellular signal-regulated kinase; FGFR3, fibroblast growth factor receptor 3; FoxO1, fork head transcription factor 1; FoxP3, forkhead box P3; GCH1, guanosine-5'-triphosphate cyclohydrolase 1; GHR, growth hormone receptor; GR, glucocorticoid receptor; GUCY, guanylate cyclase; HECT, homologous to the E6-AP carboxyl terminus; HIF-1 $\alpha$, hypoxia-inducible factor-1 alpha; Hip, Hsc70 interacting protein; Hop, Hsp70/Hsp90 organizing protein; HSF1, heat shock factor 1; HspB8, heat shock protein B8 hTERT, human telomerase reverse transcriptase; ICER, inducible cyclic activated protein kinase (AMP) early repressor; IRE1, inositol requiring enzyme 1; IRF1, interferon regulatory factor 1; JNK, c-Jun N-terminal kinase; LC3, microtubuleassociated protein 1A/1B-light chain 3; LKB1, liver kinase B 1; LRRK2, leucine-rich repeat kinase 2; MAPK, mitogenactivated protein kinase; MDM2, mouse double minute 2 homolog; MEKK2, MAPK/ERK kinase kinase 2; MIF, migration inhibitory factor; MKKS, McKusick-Kaufman syndrome protein; MLK3, mixed-lineage kinase 3; nAChRs, neuronal nicotinic acetylcholine receptors; NFkB, nuclear factor $\kappa B$; NPM-ALK, nucleophosmin-anaplastic lymphoma kinase; Pael-R, ParkinAssociated Endothelin Receptor-Like Receptor; PI3K, phosphoinositide 3-kinase; PKC $\zeta$, protein kinase C $\zeta$; PRMT5, protein arginine methyltransferase 5; PTEN, phosphatase and tensin homolog deleted on chromosome TEN; PTK6, protein tyrosine kinase 6; Raf1, rapidly accelerated fibrosarcoma 1; RING, Really Interesting New Gene; Ron, recepteurd'originenantais kinase; Runx1, runt-related transcription factor 1; SENP3, SUMO/sentrin protease 3; SEREX, serologic identification by recombinant expression cloning; SGK1, serum and glucocorticoid-regulated kinase-1; SirT6, Sirtuin6; Smads, Sma-mother against decapentaplegic; SOD1, superoxide dismutase1; Src, sarcoma viral oncogene homolog; SRC3, steroid receptor coactivator-3; STUB1, STIP1 homology and U-Box containing protein 1; Tal1/Sc1, T-Cell acute lymphocytic leukemia 1; TDP-43, TAR DNA-binding protein 43; TPR, tetratricopeptide repeat; TRAF2, TNF receptor-associated factor 2; TRAT, T cell receptor associated transmembrane adaptor 1; UFD2, ubiquitin fusion degradation 2; UPS, Ubiquitin Proteasome System; XRCC1, X-ray repair cross-complementing group-1. 
CHIP targets misfolded proteins for their degradation through proteasome, as well as autophagy; simultaneously, with the help of chaperones, it also regulates folding attempts for misfolded proteins. The broad range of CHIP substrates and their associations with multiple pathologies make it a key molecule to work upon and focus for future therapeutic interventions. E3 ubiquitin ligase CHIP interacts and degrades many protein inclusions formed in neurodegenerative diseases. The presence of CHIP at various nodes of cellular protein-protein interaction network presents this molecule as a potential candidate for further research. In this review, we have explored a wide range of functionality of $\mathrm{CHIP}$ inside cells by a detailed presentation of its co-chaperone, E3 and E4 enzyme like functions, with central focus on its protein quality control roles in neurodegenerative diseases. We have also raised many unexplored but expected fundamental questions regarding CHIP functions, which generate hopes for its future applications in research, as well as drug discovery.

Keywords: E3 ubiquitin ligases, misfolded proteins, neurodegeneration, cell death, aging

\section{INTRODUCTION}

A nascent polypeptide chain achieves its native structure with the help of folding machinery present inside the cells that includes molecular chaperones and other associated proteins. However, many of these proteins are not able to fold properly and are needed to be cleared from the cell by the cellular protein quality control system that includes mainly ubiquitin proteasome system (UPS) and autophagy. These two systems either work independently or in collaboration with each other (Goldberg, 2003; Korolchuk et al., 2010). Molecular chaperones are the supervisors of newly synthesized polypeptides in the crowded cellular milieu. The guidance of chaperones assists immature polypeptides to acquire a functional macromolecular structure and move towards appropriate cellular localization to perform pre-defined functions (Ellis and Hemmingsen, 1989; Hartl, 1996). Two well-studied chaperones are heat shock proteins, Hsp70 and Hsp90. Heat shock proteins function as stress-induced proteins to monitor changes in the molecular environment of the cell (Nollen and Morimoto, 2002). The chaperones not only assist new proteins in achieving the functional activity by proper folding, but also play crucial roles in removal of aberrant proteins, either by UPS or by autophagy pathway (Hartl et al., 2011).

Chaperones participate in protein quality control processes of the cell by forming complexes with E3 ubiquitin ligases, ubiquitin molecules, various accessory co-chaperones (Hsp40, BAG-1, BAG-3, etc.) and other proteins to tag misfolded or improperly folded proteins for their removal from the cells (Edkins, 2015). UPS involves ubiquitin-dependent degradation of various misfolded proteins (Ciechanover, 1994; Hochstrasser, 1996). UPS consists of three enzymes E1 ubiquitin activating enzyme, E2 ubiquitin conjugating enzymes and E3 ubiquitin ligases. Other than these enzymes a small 76 amino acid long ubiquitin protein, and $26 \mathrm{~S}$ proteasome, the proteolytic machinery of the cell with different types of protease activities, are other major components of the UPS (Hershko, 1998). As shown in Figure 1A, ubiquitination of a particular protein, with the help of successive activities of E1, E2 and E3 enzymes generates a degradation signal onto a protein, for its translocation to the $26 \mathrm{~S}$ proteasome interior, where the catalytic sites of proteasome cleave polypeptide into smaller oligopeptides. The specificity in the functioning of UPS comes from E3 ubiquitin ligase enzymes, which recognize misfolded proteins and continue their elimination through catalytic activities of $26 \mathrm{~S}$ proteasome (Pickart, 2001).

Autophagy is another widely explored pathway that helps in clearance of the cytoplasmic bulk of misfolded proteins, by using lysosomal proteolysis (Seglen and Bohley, 1992). The cytoplasmic bulk includes aggregates, oligomers, protein complexes, misfolded soluble proteins and sometimes cellular organelles. Autophagic degradation begins with the formation of the double-layered membrane, the phagophore, that is designated as autophagosome when wrapped around autophagic substrates. The tag of autophagosomal markers, like p62 helps in the transportation of autophagosome to lysosome for final degradation by lysosomal hydrolases (Korolchuk et al., 2010). Chaperone-assisted selective autophagy (CASA) and chaperone-mediated autophagy (CMA) are examples of two types of autophagy, where chaperones are involved in protein degradation, using this lysosomal pathway (Kaushik and Cuervo, 2012). Chaperone-assisted proteasomal degradation (CAP) elucidates another mechanism where chaperones steer misfolded proteins towards the ubiquitinmediated proteasomal degradation (Kettern et al., 2010). Chaperones are also responsible for the crosstalk between these two pathways of protein degradation (Park and Cuervo, 2013).

C-terminus of Hsc70-interacting protein (CHIP) is profoundly involved in most of the above-described quality control pathways (Kettern et al., 2010). Previously, we have 


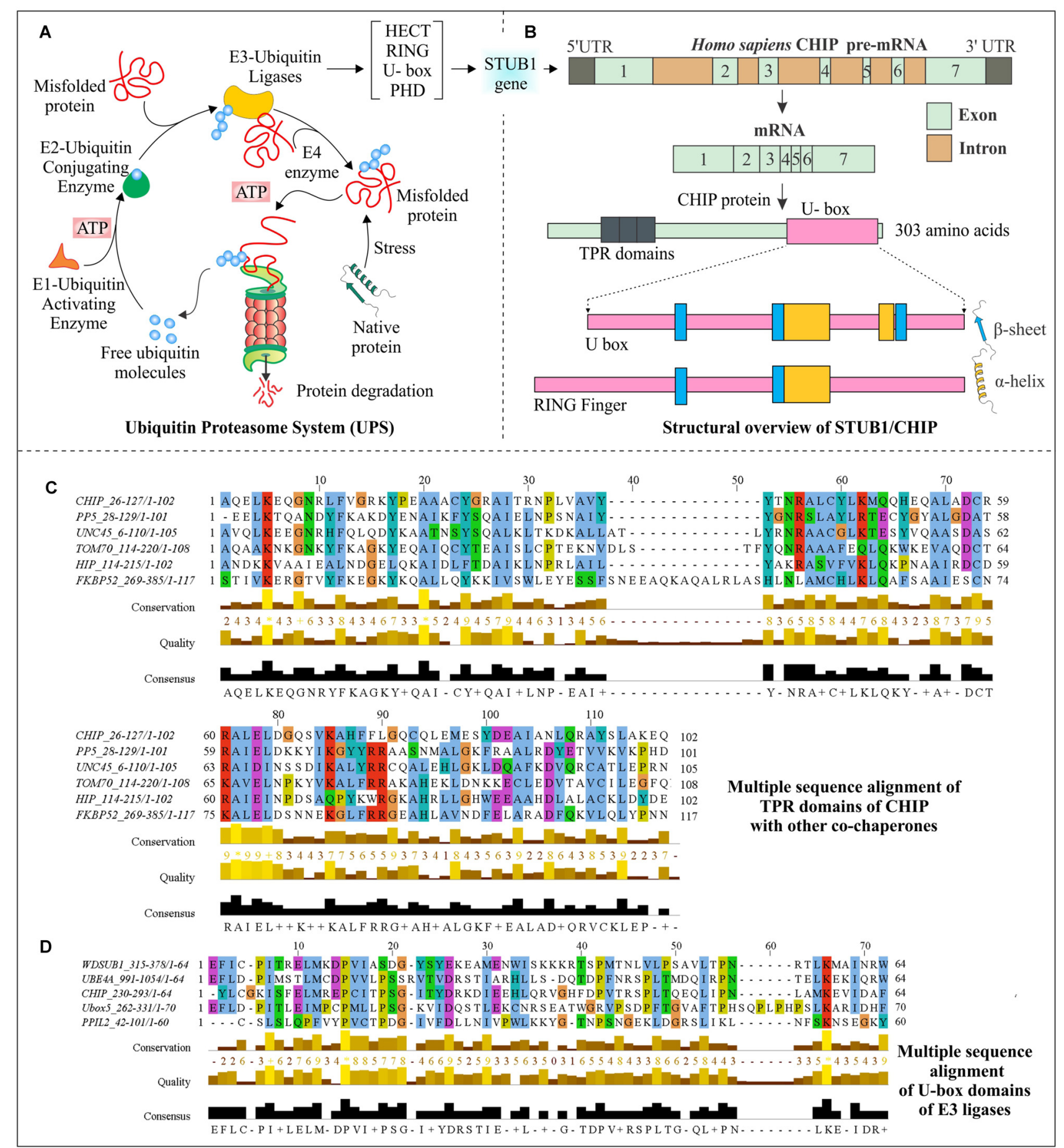

FIGURE 1 | Structural aspects of C-terminus of Hsc70-interacting protein (CHIP) and multiple sequence analysis of its domains. (A) Schematic representation of the ubiquitin proteasome system (UPS) shows an ATP-dependent ubiquitin activation by E1 ubiquitin activating the enzyme, followed by attachment of ubiquitin to E2 conjugating enzymes and later targeting misfolded proteins by specific E3 ubiquitin ligase enzymes for degradation by $26 \mathrm{~S}$ proteasome complex. (B) Human STIP1 Homology And U-Box Containing Gene 1 (STUB1) gene codes for E3 ubiquitin ligase CHIP; mRNA contains seven exons and six introns. The mRNA synthesizes a 303 amino acid long protein, which contains three tetratricopeptide repeat (TPR) domains at its $\mathrm{N}$-terminal and one U-box domain at its C-terminals. A structural comparison of U-box domain with RING finger domain has been done to illustrate the respective arrangements of $\alpha$-helices and $\beta$-sheets. (C) Sequence alignment of CHIP with other co-chaperones, showing evolutionarily conserved TPR domains. (D) U-box domains of CHIP and different E3 ubiquitin ligases have been aligned to elucidate their conserved region. Clustal Omega and Jalview were used for alignment and visualization respectively, with default coloring schemes (Clamp et al., 2004; Sievers et al., 2011). Asterisk (*) shows absolute conservation of amino acids, whereas score 0-9 followed by plus sign shows the levels of amino acid conservation. 
shown various cellular strategies embraced by E3 ubiquitin ligases in the removal of aberrant cellular proteins. Few E3 ubiquitin ligases like CHIP, cullin5, E6-AP, etc. function in association with various chaperones like Hsp70, Hsp90, etc. to maintain the quality of cellular proteins (Chhangani et al., 2013). CHIP is one of the most extensively studied E3 ubiquitin ligase associated with chaperones (Murata et al., 2001). E3 ubiquitin ligase activity of CHIP is because of its evolutionarily conserved U-box domain, which is a modified form of the Really Interesting New Gene (RING) domain which also contains a metal chelating region (Hatakeyama et al., 2001; Jiang et al., 2001). Cytoplasmic $35 \mathrm{kDa}$ protein CHIP was firstly recognized as a chaperone interacting protein because of its tetratricopeptide repeat containing (TPR) domain, which is similar to Hsp70-Hsp90 organizing protein (Hop) and Hsc70 interacting protein (Hip; Ballinger et al., 1999). Negative regulation of a substrate binding cycle of Hsc70-Hsp70 by CHIP reveals its dual role as co-chaperone as well as E3 ubiquitin ligase for protein quality control in cells (Connell et al., 2001). CHIP has also been shown as a connecting link between chaperones and proteasome system (McDonough and Patterson, 2003).

The involvement of CHIP in various physiological functions defines its worth in the maintenance of cellular homeostasis; earlier findings have described its roles in a number of pathways and diseases (Paul and Ghosh, 2015). However, its exceptional significance was found in an array of neurodegenerative disorders with greater extent (Dickey et al., 2007). Another potential reason of extensive research on CHIP is its association with a wide range of diseases, such as cardiac disorders, muscular disorders and different types of cancers (Adachi et al., 2007; Willis et al., 2008; Cao et al., 2016). In this review, we first describe structural aspects and involvement of CHIP in various quality control pathways, and then we elaborate its liaison in various diseases, with a special focus on neurodegeneration and associated disorders. Loss of neurons is more crucial than the loss of any other cell in the body, as the possibility of recovery or replacement is negligible in this case (Currais et al., 2009). Understanding and analyzing available data about molecules like CHIP, that are directly linked to multiple neurodegenerative diseases, will provide hope for the development of preventive measures for these pathologies. We, here, try to compile a detailed and descriptive analysis of CHIP and its association with neurodegenerative disorders, to focus on its wide scope in future drug discovery.

\section{JOURNEY OF CHIP: GENE TO PROTEIN}

The CHIP protein in humans is encoded by STIP1 Homology and U-Box Containing gene 1 (STUB1), with the cytogenetic band at location p13.3 on chromosome number 16. The premRNA consists of seven exons and six introns within 2760 base pairs of the CHIP/STUB1 gene. As represented in Figure 1B, human CHIP protein is of 303 amino acids in length (Ballinger et al., 1999; Shi et al., 2013). The first identification of CHIP antigen was done in chronic lymphocytic leukemia patients, using serologic identification by recombinant expression cloning (SEREX) method (Krackhardt et al., 2002). The two isoforms produced by alternate splicing are of 303 and 231 amino acid long sequences having NCBI accession: NP_005852.2 and NP_001280126.1 respectively, but no experimental confirmation for the second isoform is available.

\section{Structural Overview of CHIP Domains}

Interaction of CHIP with heat shock proteins occurs because of its TPR domain; this interaction of CHIP with C-terminus of Hsc70 or Hsp70 does not have any interference in its binding with misfolded proteins. Apart from TPR domain, its adjacent positively charged region is also significantly responsible for this interaction (Ballinger et al., 1999; McDonough and Patterson, 2003). Located at N-terminal of CHIP, this TPR domain consists of three pairs of anti-parallel $\alpha$-helices and elongated seventh helix with packed $\mathrm{N}$-terminus against its third helical pair (Zhang et al., 2005). TPR domains are structurally conserved among many other co-chaperones, which also have a tendency to bind with Hsp70 and Hsp90 (McDonough and Patterson, 2003). In a multiple sequence alignment analysis, which is presented in Figure 1C, conserved nature of this domain in CHIP and other co-chaperones are observed, giving an indication of how the interaction of CHIP occurs with chaperones and how this is directly associated with many other co-chaperones.

STUB1/CHIP is a member of U-box-containing E3 ubiquitin ligases family, which is also responsible for conferring it an E4 enzyme-like activity (Jiang et al., 2001). The conserved $\sim 70$ amino acids long U-box domain is found from yeasts to humans, in various proteins (Hatakeyama et al., 2001). Previously, only two families of E3 ubiquitin ligases, Homologous to the E6-AP Carboxyl Terminus (HECT) and RING were well characterized (Passmore and Barford, 2004; Metzger et al., 2012). But in last two decades, many U-box containing proteins were identified for their function in polyubiquitination (Aravind and Koonin, 2000; Ohi et al., 2003). They were therefore established as a new family of E3 ubiquitin ligases which are also involved in protein quality control functions (Cyr et al., 2002). The U-box domain was first identified as multiubiquitin chain forming domain in a yeast ubiquitin fusion degradation 2 (UFD2) protein (Koegl et al., 1999). Later, it was found that all mammalian U-box proteins interact with chaperones, as in the case of CHIP (Hatakeyama et al., 2004). Figure 1D compares conserved regions of CHIP U-box domain with other U-box containing E3 ubiquitin ligases obtained from multiple sequence alignment.

\section{Post-Translational Modifications of CHIP Polypeptide}

Ubiquitination is one of the ways to regulate CHIP activity. Ube2W, an E2 ubiquitin conjugating enzyme, ubiquitylates CHIP at N-terminus instead of any of its lysine residues, as observed in the mass spectrometry data. This is one type of protein modification that increases its activity of ubiquitination of substrates (Tatham et al., 2013). A similar 
type of modification has been observed in the case of CHIPUbcH5A complex, which shows unconventional ubiquitination by attaching polyubiquitin chain on CHIP, lacking specificity for any of the seven lysine residues of ubiquitin (Windheim et al., 2008). Another post-translational modification in CHIP polypeptide is phosphorylation at two serine residues $\operatorname{Ser}^{19}$ and $\mathrm{Ser}^{23}$ and also the presence of one auto-ubiquitination site Lys $^{22}$ (Graf et al., 2010). Interaction of CHIP with laforin-malin complex promotes the translocation of CHIP from the cytoplasm to the nucleus upon heat shock (Sengupta et al., 2011). These examples of different types of modifications of CHIP sheds some light on importance of this protein in cellular interactions and also describes various ways, by which cell can precisely modify its major proteins to effectively deliver their crucial functions.

\section{Pathogenic Mutations of CHIP Associated with Disorders}

Mutation in STUB1 gene is one of the genetic causes of the Gordon Holmes syndrome, an autosomal recessive type of hereditary cerebellar ataxia in association with hypogonadotropic hypogonadism (Ronnebaum et al., 2014; Shi et al., 2014). Patients with mutations in this gene shows similar neurological phenotypes, as shown by patients with a mutation in two other genes associated with this syndrome RNF216 and OTUD1 (Shi et al., 2013; de Roux et al., 2016). SCA3 mice, a disease model of Machado-Joseph disease, also showed decreased levels of CHIP. This could probably be because of an increase in affinity of ataxin-3 for CHIP, which results in such decrease in CHIP levels throughout the brain (Scaglione et al., 2011). Another study showed that mutation in STUB1 affects its E3 ubiquitin ligase activity and prevents hypoxia inducible factor-1 A (HIF1A) degradation by CMA (Ferreira et al., 2013). A critical brain disease, intracranial aneurysm (IA), also involves STUB1 mutation that contributes to vascular remodeling, related to the development of this disorder (Su et al., 2013). Study of IL-4R signaling regulation by STUB1 reveals that its mutation is linked with lung inflammation having hypersecretion of the mucus and elevated level of serum IgE (Wei et al., 2014). These mutations establish the eminent participation of this E3 ubiquitin ligase protein in many pivotal metabolic pathways and developmental stages.

\section{FUNCTIONAL PLASTICITY OF CHIP}

Till date, more than 600 E3 ubiquitin ligases of different domains, properties and activities have been identified, and search is still on (Li W. et al., 2008). CHIP is important because of its functional relevance in overall working and regulation of the cell proteins. CHIP orchestrates regulation of cellular proteins from folding to degradation by various mechanisms, including a coordinated function with molecular chaperones to refold the unfolded protein species, as well as a welldirected degradation of those, which are beyond the refolding range, via proteasome or autophagy. So, to accomplish such a wide range of responsibilities, it should be a multifaceted molecule (Connell et al., 2001). To perform this task, CHIP has evolved various ways to ubiquitinate its substrates by interaction with different E2 conjugating enzymes that form a variety of signals, according to which it decides the fate of substrates. E2s are the family of enzymes, having highly conserved ubiquitin conjugating domain. These enzymes, in combination with E3s, play an important role in determining the fate of substrate proteins, by selecting a lysine residue, on which ubiquitin moiety must be added. NMR studies provide evidence that E2 enzymes require a well conserved S-P-A motif in loop seven, which is found in many E2 enzymes, to recognize and bind with CHIP. The specificity that determines the binding of UbcH5 and Ubc13-Uev1a, the E2 ubiquitinconjugating enzymes, with CHIP E3 ubiquitin ligase is their S-P-A motif. It also interacts with Ube2e2, the class III E2 enzyme because of this conserved S-P-A motif, providing the significance of this motif in such kind of interactions between U-box containing E3 ligases and associated E2 enzymes (Xu et al., 2008).

The mechanism of polyubiquitination by binding of Ubc13Uevla and UbcH5 with CHIP differ from each other as Ubc13Uevla association causes Lys $^{63}$-linked polyubiquitination, whereas ubiquitination with $\mathrm{UbcH} 5$ does not have any specificity of a lysine residue and the polyubiquitin chain remains linked to CHIP (Windheim et al., 2008). It has been shown in another finding that interaction with $\mathrm{UbcH} 5$ causes Lys $^{48}$-linked ubiquitination and it leads to degradation of proteins (Murata et al., 2003; Schulman and Chen, 2005). An in vitro study has shown that CHIP, with the aid of UbcH5 and UbcH6, can efficiently ubiquitinate interferon regulatory factor 1 (IRF1), giving an idea of its modulation, under stress conditions (Narayan et al., 2011). Similarly, another study based on CHIP U-box domain showed that eight E2's (Ube2D1, Ube2D2, Ube2D3, Ube2E1, Ube2E2, Ube2E3, Ube2N and Ube2W) can specifically interact with this domain (Soss et al., 2011). As evident from the above studies, CHIP interacts and cooperates with different E2's. However, the basis of interaction towards a particular E2, thereby, producing different ubiquitin signals, is highly complex and still much work is needed to be done to understand this mechanism.

\section{CHIP, as a Co-Chaperone}

There are various studies that provide evidence that CHIP tightly regulates chaperones. It not only assists in the functioning of chaperones, but also promotes or inhibits their co-chaperone modulated activities. One such example is the antagonistic regulation of Hop activity, by binding of CHIP to C-terminus of Hsp70 and Hsp90, using its TPR domain. Hop generally promotes folding of proteins in conjugation with Hsp70/90 complex, with the aid of Hsp40, stimulated ATPase activity of Hsc70. But, CHIP when binds with Hsp90 through its TPR chaperone adapter domain, further recruits E2 enzymes, ubiquitinate substrate proteins and marks them for proteasomal degradation (Ballinger et al., 1999; Höhfeld et al., 2001). As shown in Figure 2, CHIP competitively dissociates p23, another Hsp90 associated co-chaperone, which promotes Hsp90- 


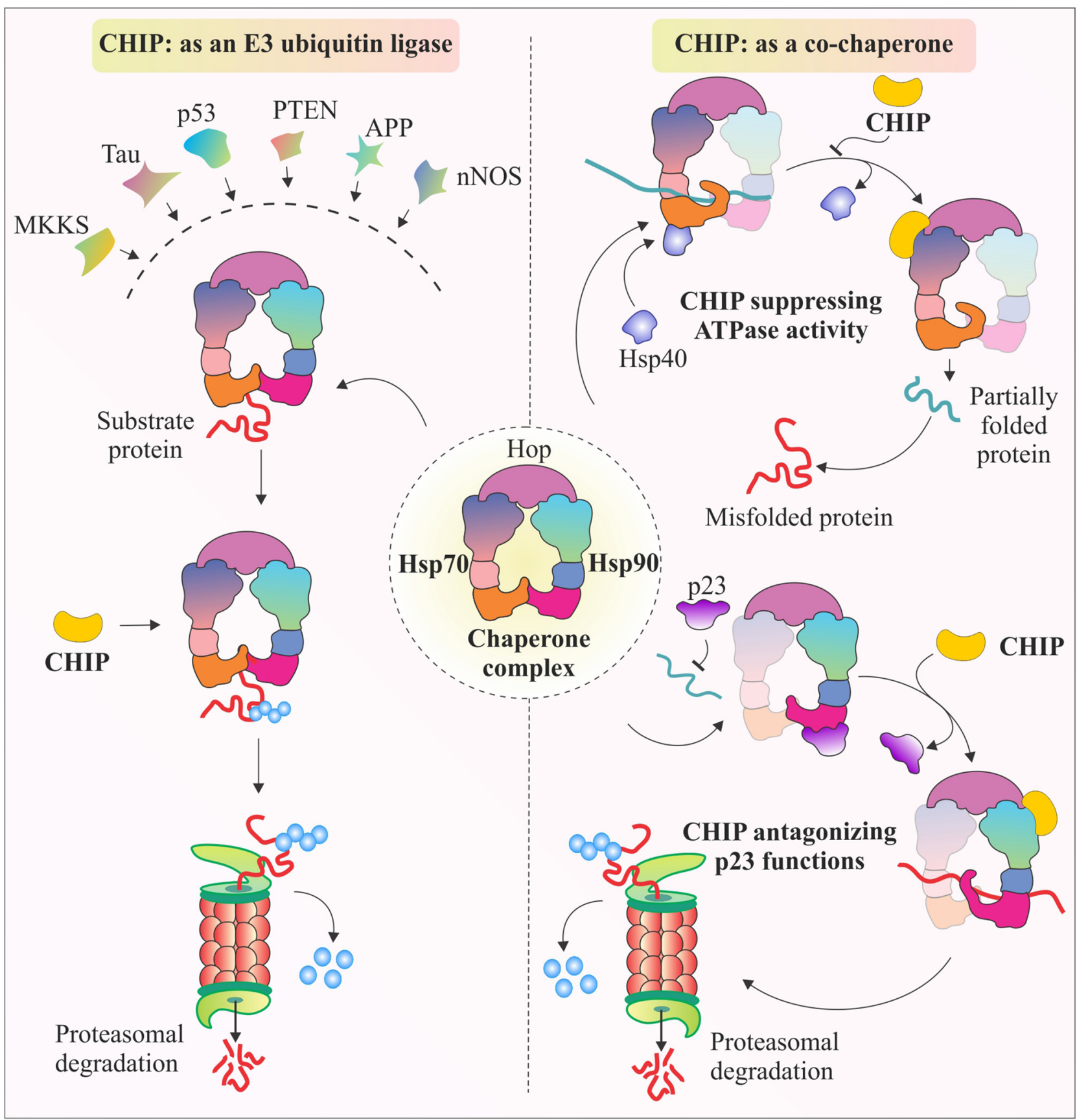

FIGURE 2 | Multifaceted CHIP, functions as E3 ubiquitin ligase and co-chaperone. The illustration represents E3 ubiquitin ligase activity of CHIP through which, it targets major class of its client proteins, when they are bound to Hsp70-Hsp90 chaperone complex. It ubiquitinates these proteins to tag them for proteasomal degradation. CHIP is also known for its co-chaperone like functioning. The figure also represents antagonistic effects of CHIP against co-chaperones Hsp40 and p23. CHIP antagonizes Hsp40 by inhibiting its ATPase activity which helps Hsp70 to fold its substrates (McDonough and Patterson, 2003). Similarly, $\mathrm{CHIP}$ binds with Hsp90, causing release of p23, resulting in ubiquitination and further degradation of substrate proteins, such as glucocorticoid receptors (GR) and erythroblastic leukemia viral oncogene homolog 2 (ErbB2; Connell et al., 2001; Höhfeld et al., 2001; Xu et al., 2002; Theodoraki and Caplan, 2012).

substrate dissociation; whereas binding of CHIP stabilizes the complex and further ubiquitinates substrate protein for degradation. Similarly, CHIP can also regulate the functionality of Hsp70 by antagonizing the effect of Hsp40 in helping the Hsp70 associated polypeptides to fold. CHIP binding inhibits substrate folding-refolding pathway directed by Hsc70/Hsp70 chaperones (Höhfeld et al., 2001; McDonough and Patterson, 2003). Binding of CHIP with chaperones has been seen as a mechanism of modulation of the activities of the major chaperones in combination with other well 
known co-chaperone proteins. Such kind of regulatory roles of CHIP over molecular chaperones gives it an extra advantage of regulating levels of various substrate proteins, apart from its regular E3 ligase like functions in degradation of proteins.

\section{CHIP, as an E3 Ubiquitin Ligase}

Similar to RING domain E3 ubiquitin ligases, which have a zinc binding motif, U-box domain containing E3 ubiquitin ligases use salt bridges and hydrogen bonds to stabilize their threedimensional structures and perform their functions (Aravind and Koonin, 2000). The presence of U-box domain in CHIP led scientists to identify its potential as an E3 ubiquitin ligase enzyme (Hatakeyama et al., 2001). Till now, multiple evidence have been established and identified a wide and diverse array of substrates, which have been shown to be associated with CHIP with or without chaperones (Dickey et al., 2007; Faresse et al., 2010). These substrates then get ubiquitinated and degraded by either proteasomal or lysosomal pathways, depending upon their mode of ubiquitination, as described in detail in the next section. Interestingly, CHIP not only regulates numerous substrates, but also ubiquitinate chaperones, like Hsp70 and Hsp90 for their proteasomal degradation. As shown in Figure 2, major class of CHIP substrates are Hsp70-Hsp90 bound proteins, which are later ubiquitinated and degraded by E3 ligase activity of CHIP. Previously, it has been observed that after the depletion of substrates, CHIP may also ubiquitinate and degrade Hsp70 in a proteasomedependent manner (Murata et al., 2001; Qian et al., 2006; Dickey et al., 2007; Kundrat and Regan, 2010). This versatile capability of CHIP to ubiquitinate in an array of patterns makes this protein unique with a master control over a large variety of substrates.

\section{E4 Like Activity of CHIP}

Yeast protein UFD2 was first identified for its unique activity of binding with the ubiquitinated substrates and extends its ubiquitin chain in conjugation with other UPS components to make those substrates eligible for proteasomal degradation (Koegl et al., 1999). U-box proteins were not only identified as the third family of E3 ubiquitin ligases after HECT and RING finger families, but also reflect their activity as E4 enzymes (Hatakeyama et al., 2001). Among various E3 ubiquitin ligase enzymes, CHIP was the first to be identified for its E4 activity, in association with Parkin for Parkin-Associated Endothelin Receptor-Like Receptor (Pael-R) degradation (Imai et al., 2002). This activity makes it capable of adding further ubiquitin molecules, to form a polyubiquitin chain. It also shows the collaborative ability of CHIP with other E3 ubiquitin ligases in degradation of substrates (Hoppe, 2005). CHIP enhances the efficiency of Parkin to polyubiquitinate the Pael- $\mathrm{R}$, resulting in its degradation via the proteasome. CHIP associates with Hsp70 to make Parkin free. As a result of this Parkin-Hsp70 dissociation, the activity of E2 ubiquitin-conjugating enzymes increases, which enhances the clearance of Pael-R, by Parkin from the cell (Imai et al., 2002).

\section{CHIP: A QUALITY CONTROLLER OF CELLULAR PROTEOME}

CHIP was first identified as a cytoplasmic protein, but in later years, its functional role in the nucleus was also well established (Ballinger et al., 1999). The localization studies of CHIP with cystic-fibrosis transmembrane-conductance regulator (CFTR) proposed its colocalization at the endoplasmic reticulum membrane, to degrade it by the proteasome (Meacham et al., 2001). The role of CHIP in the cytoplasmic quality control system, later confirms its localization in the cytoplasm (Dai et al., 2005). It was found that CHIP is partly localized in the nucleus also, to perform functions like activation of heat shock factor 1 (HSF1; Dai et al., 2003). The cytoplasmic CHIP does not only take care of cytoplasmic proteins, but is also involved in the ubiquitination and degradation of mitochondrial proteins like leucine-rich repeat kinase 2 (LRRK2), a mutation in which has largely been implicated in the onset of many cases of familial Parkinson's disease (Ding and Goldberg, 2009). CHIP also ubiquitinates and degrades substrates like microtubuleassociated tau and $\beta$-amyloid precursor protein ( $\beta$-APP), which is localized in the Golgi complex (Kumar et al., 2007; Wang and Mandelkow, 2012). Hence, enormous data presented by various studies showed that function of CHIP is not confined to any special cellular location, but, it plays significant roles in the regulation of a variety of substrates, present in different cellular locations and compartments. In Figure 3, we depict the subcellular distribution of CHIP with few of its substrate proteins to evince its cellular localization and functional potency. As mentioned earlier, CHIP is involved in both pathways of protein quality control: UPS and autophagy. The subsections below describe and categorize substrates of CHIP, in accordance with their degradative mechanisms. Most of its substrates have found to be a proteasomal target, whereas some of them are degraded through the lysosomal pathway. Interestingly, few of them viz. inositol-requiring enzyme 1 (IRE1) are only modified functionally, instead of being degraded by any of these degradation pathways (Zhu et al., 2014).

\section{Ubiquitin Proteasome System and CHIP Harmony for Regulating Cellular Functions Under Stress Conditions}

To describe the involvement of CHIP in the UPS, it is important to explain how different substrates are degraded by using proteasomal machinery. The list of CHIP substrates begins with heat shock protein Hsp70, which is not only functionally regulated by CHIP, but is also degraded through the proteasomal pathway by its E3 ubiquitin ligase activity (Qian et al., 2006). CHIP efficiency of ubiquitination and proteasomal degradation is higher for Hsp70 than Hsc70, although, these two are highly similar in structure and homologous in sequence. There is also a difference in the distribution of multiple ubiquitin chain formation by CHIP among these two proteins (Soss et al., 2015). Recently, studies on lens epithelial cells reported that knockdown of CHIP affects the Hsp70 level during heat stress, the concentration of Hsp70 in those cells is less, as 


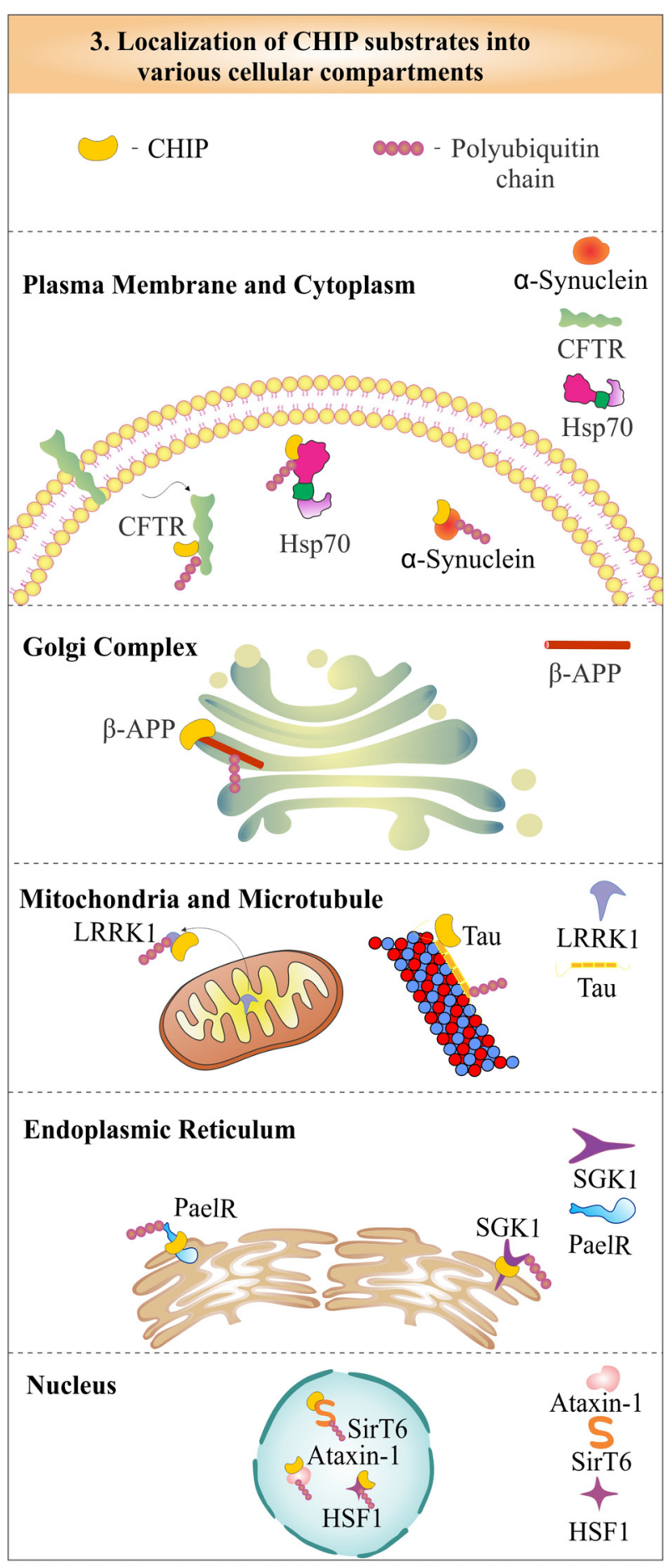

FIGURE 3 | Represenation of subcellular localization of CHIP in various cellular compartments. CHIP is widely distributed in most of the subcellular compartments, including nucleus, cytoplasm, endoplasmic reticulum and plasma membrane, in association with its substrates.

compared to negative control cells (Zhang et al., 2015). The mouse model of ischemia/reperfusion-induced heart injury also suggested that CHIP suppresses Hsp70 in the heart (Zhao et al., 2012). Molecular chaperone Hsp70, in complex with
CHIP, leads to ubiquitination and elimination of various cellular proteins, whereas Hsp90 and their client protein complexes need to be destabilized first and then their ubiquitination and removal takes place (Pratt et al., 2015). It was further illustrated by a study, in which CHIP along with Hsp90 controls the stabilization and degradation of proteins such as aryl hydrocarbon receptor (AhR) and SUMO/sentrin protease 3 (SENP3), which is involved in cellular response to mild oxidative stress (Morales and Perdew, 2007; Yan et al., 2010). The optimal levels of DNA polymerase $\beta$, DNA ligase III and X-ray repair cross-complementing group-1 (XRCC1), the base excision repair enzymes, are maintained by proteasomal degradation, through CHIP (Parsons et al., 2008; Sobol, 2008). All these examples show the cytoprotective nature of CHIP under various stress conditions including heat shock, oxidative stress and DNA damage etc.

\section{Molecular Functions of CHIP in the Regulation of Signaling Pathways and Cellular Proliferation}

The proteins, which are regulated by CHIP, are shown to be involved in many signaling pathways, and thus a dysregulation may finally lead to a condition of cancer, neurodegeneration, and other stress-related pathologies (Shang et al., 2014). The signaling kinases like AKR/J thyoma protein kinase (Akt), which is responsible for phosphorylation of tau and protein tyrosine kinase 6 (PTK6), that is highly expressed in various cancers are degraded by CHIP (Dickey et al., 2008; Kang et al., 2012). Regulation of signaling by CHIP was also associated with degradation of a typical protein kinase $\mathrm{C} \zeta(\mathrm{PKC} \zeta)$ and sarcoma viral oncogene homolog (Src), involved in Toll-like receptor-mediated immunity (Yang et al., 2011). Other kinases, like nucleophosmin-anaplastic lymphoma kinase (NPM-ALK) and liver kinase B1 (LKB1) are degraded by E3 ubiquitin ligase activity of CHIP (Bonvini et al., 2004; Gaude et al., 2012). Nuclear factor-kB (NF-kB), TNF receptor-associated factor 2 (TRAF2) and Caspase recruitment domain (CAD) containing membrane-associated guanylate kinase (CARMA1), key molecules participating in the regulation of the NF-kB pathway is also regulated by ubiquitination and degradation through CHIP (Jang et al., 2011; Wang et al., 2013a). The studies also found the role of CHIP in maintaining the cellular concentrations of proteins such as MAPK/ERK kinase kinase 2 (MEKK2) and mixed-linkage kinase (MLK3), which are shown to be involved in important signaling pathways, like extracellular signal-regulated kinase (ERK), mitogen-activated protein kinase (MAPK) and c-Jun N-terminal kinase (JNK) pathways, which regulate migration, invasion, proliferation and apoptosis-like important cellular phenomenon (Maruyama et al., 2010; Blessing et al., 2014). It maintains a steady level of kinases such as dual leucine zipper-bearing kinase (DLK) and serum and glucocorticoid regulated kinase-1 (SGK-1) in the cell, in complex with Hsp70 (Belova et al., 2006; Daviau et al., 2006). Hsp90 client protein, migration inhibitory factor (MIF), which is involved in many signaling pathways, is also a well-known substrate of CHIP (Schulz et al., 2012). Breakpoint cluster abelson murine leukemia viral oncogene (BCR-ABL) and C-terminal binding protein 2 (CtBP2) are other two proteins, added in this list 
of CHIP substrates (Tsukahara and Maru, 2010; Lee and Yoo, 2013).

The regulation of turnover of various receptors, that are involved in signaling processes, by CHIP, is performed by degrading proteins like glucocorticoid receptors (GR), estrogen alpha receptor $(\mathrm{ER} \alpha)$ and androgen receptor (AR), using UPS (Wang and DeFranco, 2005; Zhang et al., 2011; Sarkar et al., 2014). The E3 ubiquitin ligase function of CHIP maintains the cellular level of recepteur d'origine nantais kinase (Ron) tyrosine kinase receptor that binds with ligand macrophage-stimulating protein to give the signal for proliferation and migration of cells (Germano et al., 2006). Another protein of phosphoinositide 3-kinase (PI3K) signaling pathway, phosphatase and tensin homolog deleted on chromosome TEN (PTEN) interacts with the TPR domain of CHIP, by parts of its N-terminal domain for ubiquitination and degradation (Ahmed et al., 2012). It also regulates human telomerase reverse transcriptase (hTERT) and hence modulates telomerase activity in cancer cells (Lee et al., 2010). A tumor suppressor gene, menin, mutation in which causes multiple endocrine neoplasia type1, is rapidly degraded after being ubiquitinated by CHIP (Yaguchi et al., 2004).

CHIP is also important for the regulation of many proteins involved in the formation of tumors, known as proto-oncogenes, for example cErbB2/Neu and c-Myc (Xu et al., 2002; Paul et al., 2013). Receptor tyrosine kinase AXL, that binds to the growth arrest-specific protein 6 , regulates the progression of many cancers, is also a substrate of CHIP (Krishnamoorthy et al., 2013). Overexpression of CHIP maintains the critical cellular levels of substrate proteins and inhibits their over-accumulation, such as erythroblastic leukemia viral oncogene homolog 2 (ErbB2), a member of the receptor tyrosine kinase family that control normal cell proliferation, differentiation and migration. The new emerging anti-cancer strategies, involving downregulation of ErbB2, also focus on the CHIP-mediated degradation of this protein in association with molecular chaperones (Zhou et al., 2003). The mutant $\mathrm{p} 53$, another tumor-causing protein, is a substrate of CHIP and chaperone complex (Esser et al., 2005). Tumor cell migration regulating protein, profilin, is also a notable substrate of CHIP (Choi et al., 2014). As apoptosis signal-regulating kinase 1 (ASK1) contain TPR acceptor site, it was found that CHIP, with its TPR domain binds with this site to ubiquitinate and degrade it by the proteasome (Hwang et al., 2005). A truncated form of a mitochondrial protein, apoptosis inducing factor (tAIF) is ubiquitinated and degraded by CHIP in Hsp70 dependent manner (Oh et al., 2011). A recent study summarizes that this interaction is disrupted by cyclin-dependent kinase (Cdk5), which phosphorylates CHIP at Ser20 position. Even after this disruption, E3 ubiquitin ligase activity of CHIP remains intact, but this modification causes inhibition of tAIF proteasomal degradation and thus leads to the death of neurons (Kim et al., 2016). Endonuclease G, another mitochondrial protein, which induces apoptosis is ubiquitinated and degraded by CHIP to protect cells from cell death, induced by oxidative stress (Lee et al., 2013). Recently, it was also found that protein arginine methyltransferase 5 (PRMT5), an oncoprotein, expressing at high concentration in a number of human cancers, is negatively regulated by CHIP, which ubiquitinates and degrade PRMT5 via proteasomal degradation (Zhang et al., 2016). These line of evidence showing a diverse range of substrates, including signaling molecules, receptor proteins, various kinases, a number of oncoproteins and tumor suppressors make this protein a potential target, which, in future, may be exploited for the development of anti-cancer strategies.

\section{Cellular Functions and Relations of CHIP Associated with Other Crucial Molecular Physiological Partners}

Enzymes are also in the list of CHIP substrates, such as Hsp90 linked guanylyl cyclate (GUCY) and neuronal enzymes like neuronal nitric oxide synthase (nNOS; Peng et al., 2004; Xia et al., 2007). GTP cyclohydrolase I degradation controlled by CHIP, regulates pulmonary blood flow (Sun et al., 2011). Proteins like cytochrome 450 isoform 3A4 (CYP3A4) and $\mathrm{NAD}(\mathrm{P}) \mathrm{H}$ : quinone oxidoreductase 1 (NQO1), are also governed by CHIP for their cellular levels (Tsvetkov et al., 2011; Wang et al., 2012). The complex of CHIP/Hsp70 involves association of many other co-chaperones such as Hsp40, BAG-1 and BAG-3. These co-chaperones, especially BAG-1, facilitate the ubiquitin tagging of the substrate proteins, like rapidly accelerated fibrosarcoma 1 (Raf1), and mark them for $26 \mathrm{~S}$ proteasomal destruction. BAG-1 interacts with CHIP and helps in the transfer of the substrate from Hsp70 to CHIP-mediated proteasomal degradation (Demand et al., 2001). Hsp70 bound CHIP was also observed to take part in balancing critical concentrations of proteins, such as mutant keratins and hypoxia-inducible factor- $1 \alpha$ (HIF-1 $\alpha$ ), which is a transcription factor for proteins which are up-regulated in response to low oxygen levels (Luo et al., 2010; Löffek et al., 2010). Thus, CHIP also controls adaptive responses of cells in low oxygen conditions. Other studies also suggest the involvement of CHIP in regulating the levels of other Hsp90 client proteins such as runt-related transcription factor 1 (Runx1) and LRRK2, via UPS, a protein whose mutation is linked to Parkinson's disease (Ding and Goldberg, 2009; Shang et al., 2009). Hsp90 inhibitor molecules are investigated as it has shown to control important signaling pathways, which are up-regulated in many diseases. Thus, controlling the substrate accumulation of Hsp90 client proteins by overexpressing CHIP can provide options for treatment of various pathologies (Pratt et al., 2015). The roles of $\mathrm{CHIP} / \mathrm{Hsp} 70$ in regulation and selective removal of aggregated protein inclusions from the cell in various neurodegenerative disorders cannot be neglected. A detailed picture of its involvement in various neurological disorders has been presented in the later section of this review.

Other anomalies of the genetic disorders such as McKusickKaufman syndrome (MKKS), includes removal of mutant MKKS protein from the cell by CHIP (Hirayama et al., 2008). Translation-transcription regulators like eukaryotic translation initiation factor $4 \mathrm{E}$ (eIF4E), a forkhead transcription factor 1 (FoxO1) and histone deacetylase 6 (HDAC6) are also ubiquitinated and degraded by proteasomal degradation via CHIP interaction (Murata and Shimotohno, 2006; Li et al., 2009; Cook et al., 2012). The E3 ubiquitin ligase CHIP is also responsible for degradation of myocardin and katanin 
p60, hence, affects the differentiation in smooth muscle cells and axonal growth, respectively (Xie et al., 2009; Yang et al., 2013). The cardioprotective effect of CHIP is also because of ubiquitination and degradation of inducible cyclic AMP early repressor (ICER; Woo et al., 2010). Geldanamycin (Hsp90 inhibitor) induces the degradation of estrogen receptor alpha; CHIP not only increases this effect, but also maintains the basal level of this receptor (Fan et al., 2005). Sma-mother against decapentaplegic 1 (Smad1) and Smad4 are both coexpressed with the CHIP, and it was found that Smad1 is preferentially degraded by the proteasome to block bone morphogenetic proteins (BMP) signal transduction (Li et al., 2007). In the case of interferon regulating factor (IRF-1), trichostatin A treatment to cells causes enhanced proteasomal degradation of IRF-1, by association with CHIP (Gao et al., 2013). CHIP interaction with Hsp70 also controls the critical level of neuronal nicotinic acetylcholine receptors (nAChRs), which are involved in ganglionic transmission and take part in smoking-related diseases (Teng et al., 2015). Interaction of CHIP and Hsp70-Hsp90 chaperones largely regulate a broad range of proteins, which are part of crucial and important regulatory pathways. Regulatory control over transcriptional and translational regulators designates CHIP as a master controller of such a large network of proteins which play critical roles in cellular metabolism, signaling and proliferation.

\section{CHIP-Mediated Autophagic Degradation with the Help of Chaperones}

Studies found that CHIP also plays a crucial role in maintaining cellular level of many crucial proteins, by using the degradation pathway of autophagy. It has been observed that CHIP/Hsp70 complex alleviates cells from the proteotoxic stress generated by phosphorylated tau and mutant alpha-synuclein by using both the systems of UPS and autophagy (Shin et al., 2005; Wang and Mandelkow, 2012; Chesser et al., 2013). Regulation of HIF1 by CHIP also involves oxygen dependent proteasomal degradation and CMA (Luo et al., 2010; Ferreira et al., 2013). Various other regulatory proteins and cochaperones are found to be associated with $\mathrm{CHIP} / \mathrm{Hsp} 70$ complexes to reduce the proteotoxic load of the cell by using autophagy, one such protein is growth hormone receptor (GHR). Endocytosis of GHR is controlled by mainly two types of modifications: phosphorylation and ubiquitination by CHIP (Slotman et al., 2012; Sedek et al., 2014). A coordination of CHIP and Hsp70 with molecules such as BAG3, heat shock protein B8 (HspB8), directly control client proteins using the machinery of autophagy, a process known as CASA (Gamerdinger et al., 2011). Filamin, the Z-disk maintaining protein is ubiquitinylated and degraded by CHIP through CASA, so that actin can anchor properly in striated muscles (Arndt et al., 2010). This mechanism helps to maintain the integration of $Z$ line and prevents muscle weakness. Other studies suggest HspB8, BAG3 and CHIP/Hsp70 complex effectively causes solubilization and thus eliminates aggregates of mutant superoxide dismutase (SOD1)

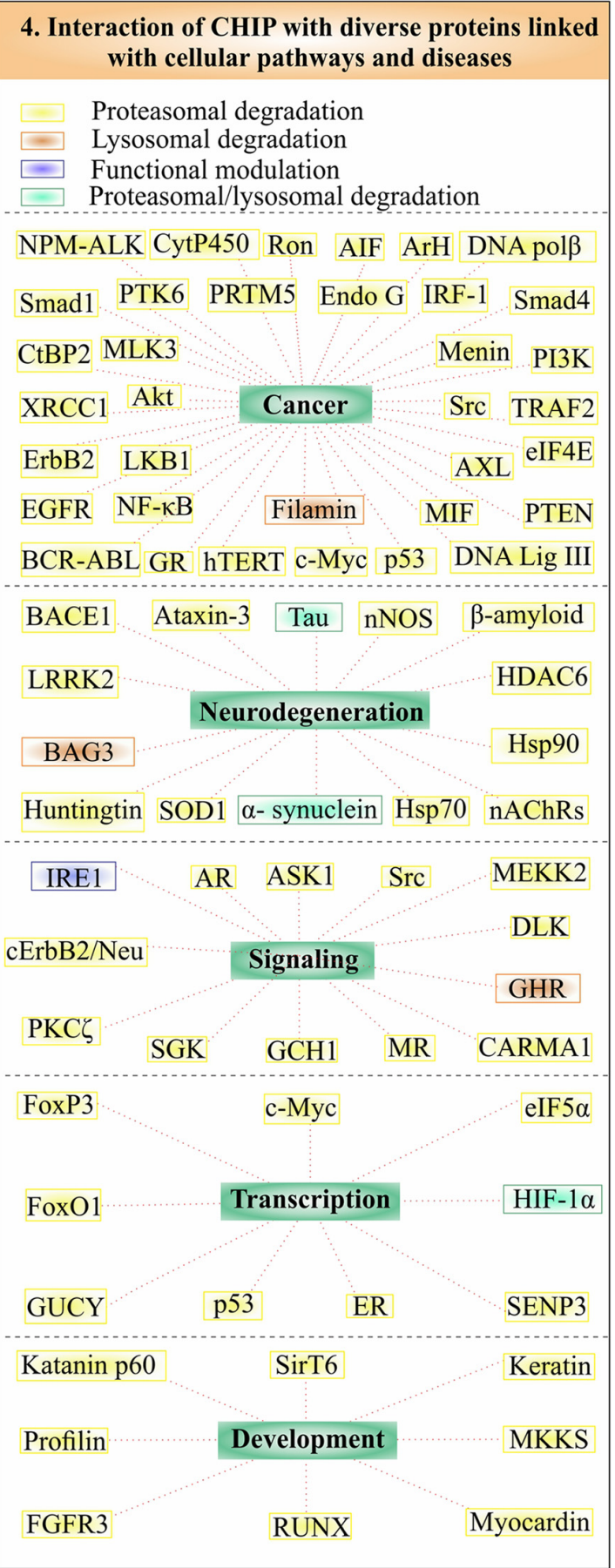

FIGURE 4 | CHIP linked substrates in multiple cellular pathways and abnormalities. CHIP substrates form a large group of proteins, implicated in various important pathways and pathologies. Substrates are subdivided in accordance with their association with cancer, neurodegeneration, signaling, transcriptional regulation and development. Substrates have been put into different boxes according to their degradative pathways. Yellow boxes represent substrates, which are degraded by the proteasome, whereas brown boxes represent the lysosomal degradation of CHIP substrates. Substrates degraded by both proteasomal and lysosomal pathways are shown in the green box. CHIP also ubiquitinates few of its substrates to functionally regulate them instead of degrading, shown within the purple box. 
via the mechanism of autophagy. The autophagic flux of many substrates in the cell is controlled by CHIP, as observed in CHIP knockdown cells, where it regulates autophagic marker proteins such as p62 and microtubule-associated protein 1A/1Blight chain 3 (LC3; Guo et al., 2015). In Figure 4, we tried to categorize the substrates of CHIP in accordance with pathways, through which they are degraded and diseases, where these proteins are involved. The ability of CHIP to degrade its substrate proteins by multiple quality control pathways, make its presence crucial for maintainance of cellular proteome balance.

\section{CHIP, A MOLECULE ASSOCIATED WITH MULTIPLE NEURODEGENERATIVE DISEASES}

In the above section, we have described the role of CHIP in quality control pathways, to maintain healthy cellular proteome. It is evident from earlier research works, done by different groups that most of the neurodegenerative diseases start developing with few common pathological hallmarks (Jellinger, 2001). Extra- or intracellular stresses and simultaneously, insufficient functioning of various arms of cellular protein quality control machinery may lead to structural modifications of some class of cellular proteins, which may form misfolded oligomers. In many cases, they start accumulating and forming inclusion bodies by entangling with other functional cellular proteins, as evident from microscopic analyses of different diseased brain tissues (Irvine et al., 2008). Such kinds of toxic proteinaceous species may lead to an array of neurological disorders e.g., Alzheimer's disease, Parkinson's disease, Huntington's disease, Amyotrophic lateral sclerosis (ALS) and Lafora disease, etc. (Dickey et al., 2007).

An interesting study in model organisms for identification of common genetic modifiers of neurodegenerative diseases has also shown the importance of CHIP (Chen et al., 2012). The gene expression analysis data of SAMP8 mouse model of Alzheimer's disease by cDNA microarray technique, form a protein network where CHIP represents an important node, which signifies its influence on the disease (Cheng et al., 2013). In Figure 5, we summarized the roles of CHIP in different neurodegenerative disorders, where we have shown its association with the misfolded proteins. Here, in this section of the review, we are focusing on various roles attributed to E3 ubiquitin ligase like activities of CHIP, in various neurodegenerative diseases.

\section{Alzheimer's Disease}

The evidence points towards two major hypotheses as causative factors for this severe neurodegenerative disease. The disease begins with the formation of intracellular neurofibrillary tangles

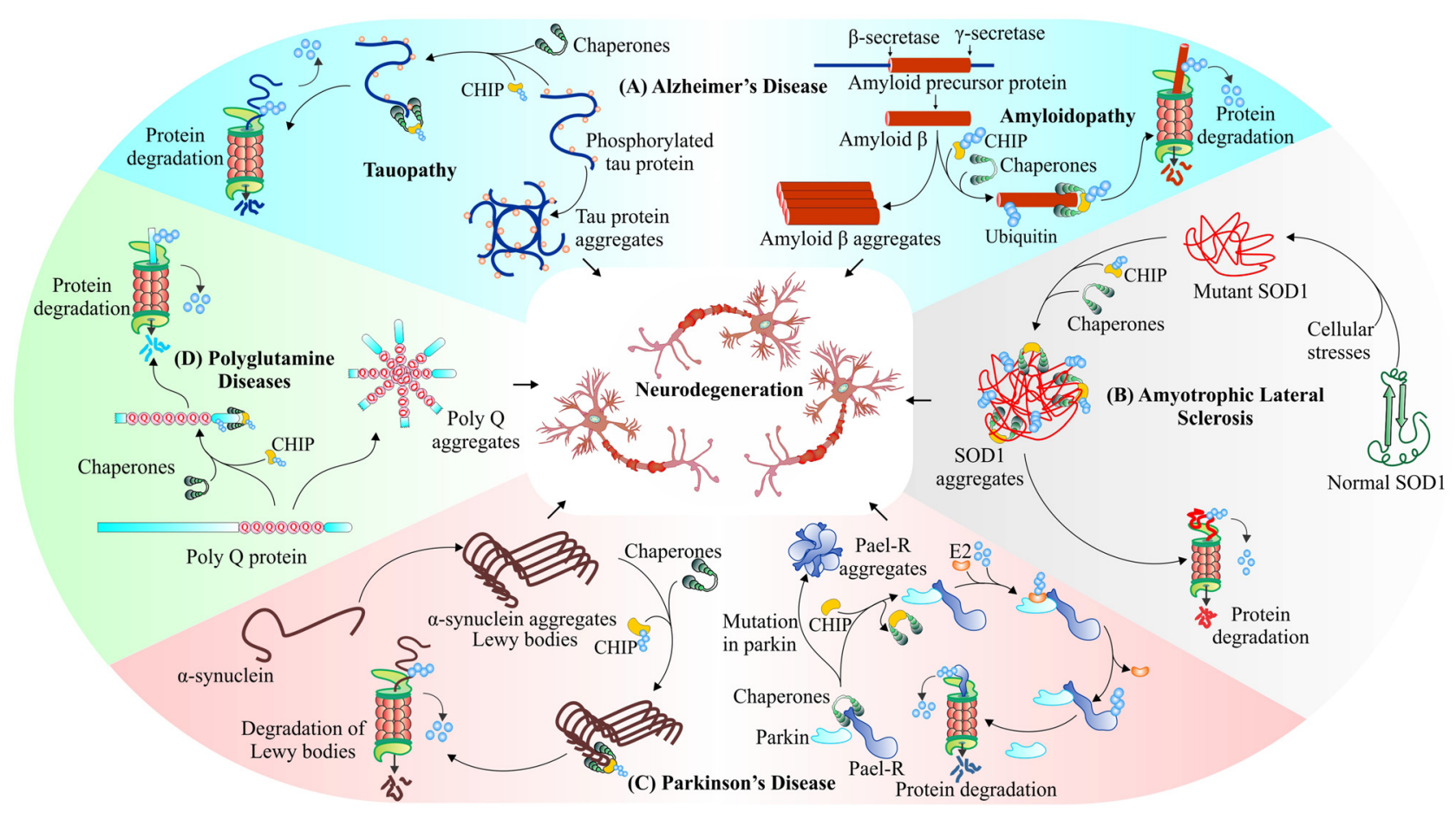

FIGURE 5 | CHIP, a major E3 ubiquitin ligase of neurodegenerative disorders. CHIP ameliorates proteotoxicities in various proteinopathies. Studies have shown that CHIP targets phosphorylated tau (Petrucelli et al., 2004; Qian et al., 2006; Koren et al., 2009), beta-amyloid (Kumar et al., 2012) in Alzheimer's disease (A), mutant superoxide dismutase (SOD1) aggregates (Urushitani et al., 2004) in Amyotrophic lateral sclerosis (ALS; B), Parkin-Associated Endothelin Receptor-Like Receptor (Pael-R; Imai et al., 2002; McDonough and Patterson, 2003; Kumar et al., 2012), alpha-synuclein (Shin et al., 2005) in Parkinson's disease (C) and polyglutamine protein aggregates (Jana et al., 2005; Williams et al., 2009) in polyglutamine diseases (D), for their proteasomal degradation. 
of phosphorylated tau, a modified form of microtubuleassociated tau protein, as the major cause of Alzheimer's (Binder et al., 2005). In vivo studies clearly suggests that in conjugation with UbcH5B, an E2 enzyme, CHIP-Hsp70 complex polyubiquitylates phosphorylated form of tau in both $\mathrm{K} 48$ as well as K63 linked manners and directs it for proteasomal or autophagic degradation respectively (Petrucelli et al., 2004). A second hypothesis, explaining the processing of amyloid precursor protein (APP) by $\beta$-secretase, leads to accumulation of amyloid beta $(\mathrm{A} \beta 42)$ peptide fragments and then formation of extra-cellular amyloid plaques, causing neuronal loss of function or synaptic loss, and in later stages loss of neurons may lead to death (Adalbert et al., 2007). Previous studies showed that colocalization of CHIP with APP stabilizes its normal cellular form; the same study also identified the involvement of CHIP in conjugation with Hsp70 and Hsp90, in suppressing accumulation of toxic A 342 peptide (Kumar et al., 2007). CHIP, therefore, enhances overall cellular health, with increased rate of cell survival (Shimura et al., 2004; Chesser et al., 2013). In Figure 5A, we have shown the interaction of CHIP with both these toxic proteins and their removal through the proteasomal pathway. The phosphorylated tau and $\beta$-amyloid interact with CHIP. This interaction further leads to ubiquitination and proteasomal degradation of these proteins.

\section{Amyotrophic Lateral Sclerosis}

The other well-known neurodegenerative disorder, ALS, which occurs due to mutations in SOD1, an antioxidant enzyme, present on mitochondrial membranes and TAR DNA-binding protein-43 (TDP-43), includes the roles of E3 ubiquitin ligase CHIP. It mediates polyubiquitination of $\mathrm{Hsp} 70 / \mathrm{Hsc} 70$, which preferentially promotes degradation of SOD1 via $26 \mathrm{~S}$ proteasome, as shown in Figure 5B (Urushitani et al., 2004). The overexpression of CHIP decreases cytotoxicity in cultured human cells by reducing levels of mutant SOD1 together with Hsp70/Hsc70 and Hsp90 (Choi and Lee, 2010). The degradation of mutant SOD1 protein through autophagy is carried out by Bag3/HspB8/Hsc70/CHIP complex that inserts mutant protein into autophagosome (Crippa et al., 2010). Another study describes increasing efficiency of Dorfin ligase by the development of Dorfin-CHIP fusion protein for degradation of mutant SOD1 protein (Ishigaki et al., 2007). Further research on the involvement of CHIP in targeting proteinaceous aggregates apart from SOD1, which is involved in ALS, will contribute in identifying its potential roles in ameliorating such kind of proteinopathies. TDP-43, cytoplasmic inclusions are another hallmark of ALS. These aggregates of TDP-43 interact with HDAC6, a substrate of CHIP/Hsp70. The complex of HDAC6/CHIP/Hsp70, in normal conditions, has the capability of deacetylating TDP-43, but they fail in case of oxidative stimuli of high potency (Cohen et al., 2015).

\section{Parkinson's Disease}

Parkinson's disease also involves the formation of various proteotoxic inclusions inside the neurons, which may later result in dementia or in extreme cases, the death of patients (Irvine et al., 2008). The inclusions forming proteins of this disease are Pael-R, $\alpha$-synuclein and LRRK2. Pael-R, a G-protein coupled receptor when accumulates in endoplasmic reticulum causes ERstress that leads to neuronal death by an unexplored mechanism (Uversky and Fink, 2007; Ko et al., 2009). CHIP mediates the dissociation of Hsp70 and Parkin, a known E3 ubiquitin ligase of Pael-R, increases the ubiquitination of Pael-R and subsequent degradation by UPS (Imai et al., 2002). Lewy bodies are the cytoplasmic fibrillar aggregates of $\alpha$-synuclein, known as a pathological hallmark of Parkinson's disease (Irvine et al., 2008). Overexpression of CHIP in cell culture models showed its colocalization with $\alpha$-synuclein and Hsp70 and a reduction in levels of $\alpha$-synuclein associated inclusion bodies; it also caused alteration in the morphology of these inclusions. The direct interaction of CHIP and $\alpha$-synuclein shows that clearance of $\alpha$ synuclein is not only carried out by proteasomal degradation, but is also mediated by lysosomal pathways (Shin et al., 2005).

The oligomeric form of $\alpha$-synuclein is preferentially recognized by CHIP for degradation in the TPR domain dependent and U-box independent manner (Tetzlaff et al., 2008). In further studies, it was observed that the ubiquitination of $\alpha$-synuclein is regulated by BCL-2-associated athanogene 5 (BAG5), it changes CHIP ability of reducing $\alpha$-synuclein oligomerization (Kalia et al., 2011). As shown in Figure 5C, the above two described Parkinson's linked protein Pael-R and $\alpha$-synuclein are degraded by CHIP-mediated ubiquitination. A mutation in mitochondria-associated LRRK2 protein is found to be involved in the onset of familial Parkinson's disease have also been reported as a substrate of CHIP (Ding and Goldberg, 2009; Ko et al., 2009). Another important role, this E3 plays, is to maintain the mitochondrial integrity, its homeostasis and overall functional health. CHIP knockout mice have impaired mitochondria, showing defective mitophagy, malfunctioned antioxidant defense and increased overall protein oxidation with elevated levels of mitochondrial stress related proteins. Increase in cellular protein and lipid oxidation are the major causes of motor impairments; deficiency of CHIP generates an oxidative insult which may lead to a decrease in neuronal survival (Palubinsky et al., 2015).

\section{Polyglutamine Diseases}

Polyglutamine diseases like Huntington's disease and Spinocerebellar ataxia, also have involvement of CHIP substrate proteins. Co-immunoprecipitation studies of CHIP and polyglutamine-expanded proteins, huntingtin and ataxin-3 demonstrated CHIP's role in polyglutamine diseases. E3 ubiquitin ligase CHIP along with Hsp70 ubiquitinates and degrades polyglutamine aggregates of mutant huntingtin and ataxin-3 (Jana et al., 2005; Dikshit and Jana, 2007), as depicted in Figure 5D. In further studies, Huntington's disease cell models, primary neurons and zebra fish models show a reduction in aggregates by the co-chaperone activity of CHIP. Also, CHIP haploinsufficient mouse models showed an accelerated disease phenotype giving an idea of the protective nature of CHIP (Miller et al., 2005). Similarly, in fly-model of Spinocerebellar 
ataxia, with wild type and polyglutamine expanded ataxin-1, CHIP was shown to reduce toxicity (Al-Ramahi et al., 2006). CHIP ubiquitinates and degrades ataxin-1, decreases its solubility, that causes the formation of insoluble aggregates, which sequesters other misfolded proteins to provide cellular protection (Choi et al., 2007). Mice with spinal and bulbar muscular atrophy, a polyglutamine expansion disease, showed improvement on overexpression of CHIP by reducing both wild-type and poly Q-expanded androgenic receptor (Adachi et al., 2007).

\section{Lafora Disease}

An autosomal recessive disorder involving neurodegeneration, lafora disease, is a result of a mutation in either substrate laforin or its E3 ubiquitin ligase malin (Gentry et al., 2005). Lafora bodies, in this disease, are polyglucosan inclusions. CHIP associates with malin-laforin complex and translocate the same to the nucleus, resulting in the activation of cellular response through upregulation of HSF1 (Sengupta et al., 2011). Malin, which is involved in the degradation of laforin, itself, shows the tendency of aggregate formation. Mutants of malin are not stable like wild type malin, and form cytoplasmic and nuclear aggregates; co-chaperone CHIP modulates stability of malin by altering Hsp70 activity (Rao et al., 2010).

\section{ROLES OF CHIP IN DEVELOPMENT AND AGING PROCESSES}

CHIP is an E3 ubiquitin ligase that has the capability to regulate its substrate proteins, right from their folding, and up to the stages of its degradation inside cells. It associates with different chaperone complexes to monitor the folding processes, as well as different protein degradation pathways, such as proteasome and autophagy. It presents a direct connecting link between these different arms of the protein quality control system: molecular chaperones, UPS, and autophagy, as described in the above sections. Apart from playing crucial roles in protein structural modifications by its co-chaperone activity, CHIP also takes part in the development of organisms. We, here, try to emphasize few crucial roles of this E3 ubiquitin ligase in development processes. CHIP substrate Runx2 is involved in regulation of osteoblast differentiation. CHIP co-chaperone domain TPR and C-terminus of Runx2 interacts with each other and results in ubiquitination and degradation of Runx2, which suppresses differentiation of preosteoblasts into osteoblasts. It could probably be due to the repressed transcriptional activity of Runx2. On the other hand, this inhibition of Runx2 by CHIP results in increased rate of adipogenesis ( $\mathrm{Li} \mathrm{X}$. et al., 2008).

Another study showed the negative effect of the CHIP knockout on total body weight of mice. The study points out its role in the overall aging process of the organism. CHIP knockout resulted in increased rate of atrophy, which was measured by decreased size of the thymus, testis and skeletal muscles and the cardiac hypertrophy also signifies the increased rate of aging. Histological considerations were also taken into account, apart from these anatomical studies. It was found that CHIP knockout has a universal effect on the dermis, resulting in thinner dermis layers as compared to control, as well as the subcutaneous deposits of fat, which was also reduced significantly. Bone mineral density was also decreased with symptoms of kyphosis (Min et al., 2008). CHIP has also been found to be involved in early neuronal development stages. The study conducted by Yang et al. (2013) shows that CHIP regulates the level of katanin-p60 protein, which is required for the proper axonal growth in early developmental stages. CHIP antagonizes the effects of a deubiquitylating enzyme, USP47, by ubiquitinating and destabilizing katanin-p60, and hence presents an important role in axonal growth (Yang et al., 2013). Another study showed abnormal motor disturbances with altered phenotypic and behavioral functions in CHIP heterozygous mice (McLaughlin et al., 2012). CHIP may also have some indirect regulatory roles over various neurodevelopmental processes through its large number of substrates, where it regulates various proteins which are directly involved in brain development processes. For example, one of its substrates, PTEN is a key signaling molecule that have direct role in various developmental processes like neuronal differentiation and neurite growth (Li et al., 2003; Hsia et al., 2014). The cellular level of PTEN is largely regulated by its proteasomal degradation, governed by various E3 ubiquitin ligases, including CHIP (Ahmed et al., 2012). Cytoskeleton of large neurons are majorly built by cytoskeletal proteins, neurofilaments. Evidence shows that CHIP has direct involvement in proteasomal degradation of neurofilaments medium subunit of $95 \mathrm{kDa}$, which are highly damaged and decreased in the less understood mechanism of 2, 5-hexanedione mediated neuropathology. Therefore, involvement of CHIPmediated proteasomal degradation presents a regulatory mechanism to maintain the levels of neurofilament proteins (Wang Q. et al., 2011; Dale and Garcia, 2012). Although these studies indicate possibilities of CHIP involvement in various developmental processes; a lack of function of which may result in severe developmental abnormalities. These reports give us some clues to further investigate its roles in more details.

Involvement of CHIP in the regulation of aging processes is also very crucial and yet to be established completely. Apart from activation of HSF1, CHIP also affects the activity and stability of the sirtuin family of proteins, which importantly regulate DNA repair mechanisms and maintain cellular homeostasis, by providing required genomic integrity. It was observed that in mouse embryonic fibroblast and human embryonic kidney cells, CHIP knockdown causes post-translational decay of Sirtuin (SirT6) protein levels in the cells. Ubiquitination of SirT6 at K170 position by CHIP E3 ubiquitin ligase stabilizes the protein, which is rather degraded by some unknown E3 ubiquitin ligase. Such kind of positive regulation of SirT6 by CHIP provides a novel example where these two arms of DNA and protein quality maintenance systems cooperatively regulate homeostasis and aging processes (Ronnebaum et al., 2013). Exome sequencing analysis in a family affected with ataxia, found the loss of function mutation in CHIP resulting in hypogonadism and ataxia like symptoms. The reported Thr346Met mutation resulted in Gordon Holmes Syndrome and 
other accelerated aging related changes which may probably be a result of protein instability or impaired substrate binding (Heimdal et al., 2014; Shi et al., 2014). Therefore, apart from development, aging is another major area of research, where detailed reports stating direct roles of CHIP are still missing, which gives us an opportunity to dig out further, the possibilities of CHIP being targeted as a candidate for anti-aging strategies.

\section{CHIP: IMPLICATIONS IN VARIOUS DISEASES}

Apart from the above described roles of CHIP in neurodegeneration, development and aging, strong evidence has indicated the importance of CHIP in diseases, such as cancer, cardiac, muscular disorders, etc. A study in past has elucidated the potential of CHIP as a biomarker and therapeutic target in various human cancers (Sun et al., 2014). The strategies have been adapted to target E1 enzymes, chaperones, histone deacetylases, proteasomal subunits and E3 ubiquitin ligases, like mouse double minute 2 homolog (MDM2), anaphase-promoting complex (APC), etc., to treat various types of cancers with varying success (Eldridge and O'brien, 2010; Shen et al., 2013; Weathington and Mallampalli, 2014). As in renal cell carcinoma and gastric cancer, decreased CHIP expression has shown potential to serve as a potent biomarker of angiogenesis (Wang et al., 2013b; Sun et al., 2014). Similarly, in esophageal squamous cell carcinoma patients, elevated CHIP expression levels in metastatic lymph node have shown a high prognostic value (Wen et al., 2013). CHIP's ability to downregulate ErbB2 makes it a potential indicator for breast cancer patients' survival (Jan et al., 2011). Besides being extensively studied for prognostic ability, CHIP has also been induced with the help of certain small molecules.

Trehalose, a disaccharide, improves the deteriorating changes taking place in patients with ataxia due to a genetic mutation in STUB1/CHIP. Trehalose, apart from activation of autophagy, also increases the levels of CHIP and Hsp70 (Casarejos et al., 2014). Another molecule quercetin, a flavonoid present in fruits and vegetables, is a chemopreventive agent in cancer; shows its beneficiary effects by down regulating ErbB2 and upregulating its E3 ubiquitin ligase CHIP (Jeong et al., 2008). Another interesting example of using small natural molecule is gambogic acid, a xanthonoid, obtained from tree Garcinia hanburyi that inhibits the interaction of Hsp90 and mutant p53 to make it available for CHIP-mediated proteasomal degradation in cancer cells (Wang J. et al., 2011). Similarly, curcumin has been shown to induce CHIP-ErbB2 interaction, thereby reducing ErbB2 levels, a strategy shown to have an enormous potential in controlling metastasis (Jung et al., 2007). Besides these, a recent study also showed a protective effect of CHIP against ER stress-mediated cell death in the central nervous system, by preventing upregulation of $\mathrm{p} 53$ pathway and regulating unfolded protein response pathways (Cabral Miranda et al., 2015). Also, upregulating CHIP activity with Hsp90 inhibitors like 17-N-allylamino-17-demethoxygeldanamycin, for anticancer therapy could be an effective strategy (Paul et al., 2013).

Deubiquitinases (DUBs) are special class of proteases which can release ubiquitin from substrate proteins by breaking the peptide bonds in between substrate and ubiquitin molecules. Regulating DUBs activities is assumed to have some possible therapeutic benefits. Ataxin-3, one of the most studied DUB, found to have a direct interaction with CHIP along with an E2 enzyme Ube2W in degradation of its substrates. An important mechanism of regulation of DUB ataxin-3 by its ubiquitination is also present inside the cells. CHIP has shown to have the capacity to ubiquitinate ataxin-3 and in turn may have a regulatory effect on this neuroprotective DUB enzyme (Scaglione et al., 2011; Tsou et al., 2013). A different therapeutic strategy was proposed to enhance the efficacy of anticancer drugs, through CHIP, by modulating CYP3A4 functioning (Peer et al., 2011). CHIP also has a pivotal role in cardiac disorders, where it provides cardioprotection by degrading inducible cAMP early repressor in complex with extracellular stress-regulated kinase 5 (Woo et al., 2010). All the above described roles of CHIP, in various disorders elucidate its significance for future research to develop advanced strategies to control these pathological disorders. Although, CHIP is a potential molecule for effectively targeting multiple cellular targets involved in several diseases, still success in devising any notable strategy to treat any of these diseases is not reported so far. So, a precise focus on some key questions, which are yet to be answered, must be given and more conceptual understanding of its functioning inside the cell should be developed.

\section{FUNDAMENTAL CHALLENGES AND UNSOLVED PUZZLES}

Many years of research has established CHIP, as a unique molecule, which has a large number of interacting partners. An interaction network of such a wide variety of substrates enables this E3 ligase enzyme to take part, directly or indirectly, in an array of cellular functions including metabolism, signaling, proliferation and apoptosis. The structure of CHIP, consisting of both TPR and U-box domain, is also a crucial factor in deciding its functional capabilities. Performing the roles of co-chaperone and E3 ligase simultaneously needs enormous molecular capabilities, and its advantageous structure provides it an extra edge in performing these dual functions. It is still a matter of investigation how exactly these decisions are being made by CHIP, inside the cells. A major question yet to be answered is, how CHIP, in combination with other chaperones recognizes the abnormal and to be degraded substrates inside the cytoplasm. Further work in this direction will indeed aid in understanding the possible ways of identifying cellular proteins on the basis of their structural and physiological features. Several studies have been done to explore the methods of discriminating the abnormal proteins from the healthy ones, whether they are to be modified, modulated or degraded. But, a clear answer is still far from our current understanding. Major focus of research over CHIP has been given to its roles in signaling, apoptosis and 
cell proliferation. But, a line of evidence clearly indicates that this molecule has equally important contribution in maintaining the cellular homeostasis and providing protection from various stresses, which are major factors causing protein aggregation and related neurodegenerative diseases. Few possible developmental and aging-related roles of CHIP has also been observed; still a lot of research is needed to be done to understand the physiological importance of CHIP in neurodevelopmental and aging processes.

\section{KEY QUESTIONS AND FUTURE PERSPECTIVES}

Maintaining a healthy proteome is a prerequisite of a living cell. To achieve this, cells are evolved with chaperone machinery and quality control pathways that maintain proteins into proper conformation and protect cells from toxicity generated in various pathological conditions (Yerbury et al., 2016). CHIP represents a protein which links all these pathways and machinery together. It not only helps chaperones to fold proteins, but also directs misfolded proteinaceous species for their proteasomal or lysosomal degradation. Interestingly, CHIP also regulates chaperones by ubiquitination and to more surprise, it also has self-ubiquitination property, which makes it capable of regulating its own turnover (Murata et al., 2001). Despite the potential that CHIP and other E3 ubiquitin ligases have, as therapeutic agents, more data is required, and further work is needed to be done, to understand the extent of E3 ubiquitin ligases in controlling various cellular processes. Chaperoneindependent role of CHIP is still needed to be fully established, which can unveil its various other properties. How to achieve specificity, in the case of CHIP, is another criterion that should be worked upon, if this multifaceted ligase has to be used for therapeutic benefits. Being a central molecule in various processes, merely overexpressing it will also affect other pathways and substrates that could prove this strategy detrimental in place of being beneficial. So, besides looking for pathways and substrates, properties and strategies, that could increase specificity for intended substrate will undoubtedly open a new area for treating diseases that are difficult to handle, with our current treatment strategies.

Although, enough reports have been made to establish protective roles of E3 ubiquitin ligases in various

\section{REFERENCES}

Adachi, H., Waza, M., Tokui, K., Katsuno, M., Minamiyama, M., Tanaka, F., et al. (2007). CHIP overexpression reduces mutant androgen receptor protein and ameliorates phenotypes of the spinal and bulbar muscular atrophy transgenic mouse model. J. Neurosci. 27, 5115-5126. doi: 10.1523/JNEUROSCI.124207.2007

Adalbert, R., Gilley, J., and Coleman, M. P. (2007). A $\beta$, tau and ApoE4 in Alzheimer's disease: the axonal connection. Trends Mol. Med. 13, 135-142. doi: 10.1016/j.molmed.2007.02.004

Ahmed, S. F., Deb, S., Paul, I., Chatterjee, A., Mandal, T., Chatterjee, U., et al. (2012). The chaperone-assisted E3 ligase C terminus of Hsc70-interacting protein (CHIP) targets PTEN for proteasomal degradation. J. Biol. Chem. 287, 15996-16006. doi: 10.1074/jbc.M111.321083 neurodegenerative diseases, still no notable success has been registered so far to treat these life-threatening neuronal disorders. In one of our previous review articles, we have selected few such E3 ligases which have shown cellular protection against these pathological conditions (Upadhyay et al., 2015). CHIP, with an array of protein quality control functions, including regulation of chaperones and autophagic pathways, posits it as one prominent candidate, which has a huge potential to be targeted in the future therapeutic models of neurodegenerative diseases. The ability of CHIP to interact with numerous proteins and participation in multiple cellular pathways makes it one of the most interesting E3 ubiquitin ligase. CHIP, with described functions, bestows to be a possible future therapeutic target which could be exploited by the drug industry in the future. With such a significant contribution in cellular homeostasis, CHIP needs further attention of the scientific community to think and devise strategies to regulate multiple pathways of cellular importance by using this molecule. Focus on specific details and elaborated knowledge of underlying mechanisms will allow us to use CHIP as a therapeutic molecule in future.

\section{AUTHOR CONTRIBUTIONS}

VJ, AU, AA and RM, executed complete drawing of figures, AK provided critical inputs. AM formulated the entire concept of manuscript and designed the initial draft of figures. All authors reviewed the manuscript.

\section{ACKNOWLEDGMENTS}

This work was supported by Ramalinganswami fellowship: BT/RLF/Reentry/11/2010 from the Department of Biotechnology, Government of India. Extra Mural Research Funding (Individual Centric): Science and Engineering Research Board (SERB) EMR/2016/000716, Department of Science and Technology, Government of India. VJ and AU were supported by a research fellowship from University Grants Commission, Council for Scientific and Industrial Research, Government of India. The authors would like to thank Mr. Bharat Pareek for his technical assistance and entire lab management during the manuscript preparation. We apologize to various authors whose work could not be included due to space limitations.

Al-Ramahi, I., Lam, Y. C., Gouyon, B. D., Zhang, M., Pérez, A. M., Branco, J., et al. (2006). CHIP protects from the neurotoxicity of expanded and wild-type ataxin-1 and promotes their ubiquitination and degradation. J. Biol. Chem. 281, 26714-26724. doi: 10.1074/jbc.M6016 03200

Aravind, L., and Koonin, E. V. (2000). The U box is a modified RING finger-a common domain in ubiquitination. Curr. Biol. 10, 132-134. doi: 10. 1016/s0960-9822(00)00398-5

Arndt, V., Dick, N., Tawo, R., Dreiseidler, M., Wenzel, D., Hesse, M., et al. (2010). Chaperone-assisted selective autophagy is essential for muscle maintenance. Curr. Biol. 20, 143-148. doi: 10.1016/j.cub.2009.11.022

Ballinger, C. A., Connell, P., Wu, Y., Hu, Z., Thompson, L. J., Yin, L. Y., et al. (1999). Identification of CHIP, a novel tetratricopeptide repeat-containing protein that interacts with heat shock proteins and negatively regulates 
chaperone functions. Mol. Cell. Biol. 19, 4535-4545. doi: 10.1128/mcb.19.6. 4535

Belova, L., Sharma, S., Brickley, D. R., Nicolarsen, J. R., Patterson, C., and Conzen, S. D. (2006). Ubiquitin-proteasome degradation of serum-and glucocorticoid-regulated kinase-1 (SGK-1) is mediated by the chaperonedependent E3 ligase CHIP. Biochem. J. 400, 235-244. doi: 10.1042/bj200 60905

Binder, L. I., Guillozet-Bongaarts, A. L., Garcia-Sierra, F., and Berry, R. W. (2005). Tau, tangles and Alzheimer's disease. Biochim. Biophys. Acta 1739, 216-223. doi: 10.1016/j.bbadis.2004.08.014

Blessing, N. A., Brockman, A. L., and Chadee, D. N. (2014). The E3 ligase CHIP mediates ubiquitination and degradation of mixed-lineage kinase 3. Mol. Cell. Biol. 34, 3132-3143. doi: 10.1128/MCB.00296-14

Bonvini, P., Dalla Rosa, H., Vignes, N., and Rosolen, A. (2004). Ubiquitination and proteasomal degradation of nucleophosmin-anaplastic lymphoma kinase induced by 17-allylamino-demethoxygeldanamycin role of the co-chaperone carboxyl heat shock protein 70-interacting protein. Cancer Res. 64, 3256-3264. doi: 10.1158/0008-5472.can-03-3531

Cabral Miranda, F., Adão-Novaes, J., Hauswirth, W. W., Linden, R., PetrsSilva, H., and Chiarini, L. B. (2015). CHIP, a carboxy terminus HSP-70 interacting protein, prevents cell death induced by endoplasmic reticulum stress in the central nervous system. Front. Cell. Neurosci. 8:438. doi: 10. 3389/fncel.2014.00438

Cao, Z., Li, G., Shao, Q., Yang, G., Zheng, L., Zhang, T., et al. (2016). CHIP: a new modulator of human malignant disorders. Oncotarget 7, 29864-29874. doi: 10. 18632/oncotarget.8219

Casarejos, M. J., Perucho, J., López-Sendón, J. L., De Yébenes, J. G., Bettencourt, C., Gómez, A., et al. (2014). Trehalose improves human fibroblast deficits in a new CHIP-mutation related ataxia. PLoS One 9:e106931. doi: 10.1371/journal.pone. 0106931

Chen, S., Liu, A.-R., An, F.-M., Yao, W.-B., and Gao, X.-D. (2012). Amelioration of neurodegenerative changes in cellular and rat models of diabetes-related Alzheimer's disease by exendin-4. Age (Dordr.) 34, 1211-1224. doi: 10. 1007/s11357-011-9303-8

Cheng, X.-R., Cui, X., Zheng, Y., Zhang, G., Li, P., Huang, H., et al. (2013). Nodes and biological processes identified on the basis of network analysis in the brain of the senescence accelerated mice as an Alzheimer's disease animal model. Front. Aging Neurosci. 5:65. doi: 10.3389/fnagi.2013.00065

Chesser, A. S., Pritchard, S. M., and Johnson, G. V. W. (2013). Tau clearance mechanisms and their possible role in the pathogenesis of Alzheimer disease. Front. Neurol. 4:122. doi: 10.3389/fneur.2013.00122

Chhangani, D., Jana, N. R., and Mishra, A. (2013). Misfolded proteins recognition strategies of E3 ubiquitin ligases and neurodegenerative diseases. Mol. Neurobiol. 47, 302-312. doi: 10.1007/s12035-012-8351-0

Choi, J.-S., and Lee, D. H. (2010). CHIP promotes the degradation of mutant SOD1 by reducing its interaction with VCP and $S 6 / S^{\prime}$ subunits of $26 \mathrm{~S}$ proteasome. Animal Cells Syst. 14, 1-10. doi: 10.1080/19768351003765145

Choi, Y. N., Lee, S. K., Seo, T. W., Lee, J. S., and Yoo, S. J. (2014). C-Terminus of Hsc70-interacting protein regulates profilin 1 and breast cancer cell migration. Biochem. Biophys. Res. Commun. 446, 1060-1066. doi: 10.1016/j.bbrc.2014. 03.061

Choi, J. Y., Ryu, J. H., Kim, H. S., Park, S. G., Bae, K. H., Kang, S., et al. (2007). Co-chaperone CHIP promotes aggregation of ataxin-1. Mol. Cell. Neurosci. 34, 69-79. doi: 10.1016/j.mcn.2006.10.002

Ciechanover, A. (1994). The ubiquitin-proteasome proteolytic pathway. Cell 79, 13-21. doi: 10.1016/0092-8674(94)90396-4

Clamp, M., Cuff, J., Searle, S. M., and Barton, G. J. (2004). The jalview java alignment editor. Bioinformatics 20, 426-427. doi: 10. 1093/bioinformatics/btg430

Cohen, T. J., Hwang, A. W., Restrepo, C. R., Yuan, C. X., Trojanowski, J. Q., and Lee, V. M. (2015). An acetylation switch controls TDP-43 function and aggregation propensity. Nat. Commun. 6:5845. doi: 10.1038/ncomms6845

Connell, P., Ballinger, C. A., Jiang, J., Wu, Y., Thompson, L. J., Höhfeld, J., et al. (2001). The co-chaperone CHIP regulates protein triage decisions mediated by heat-shock proteins. Nat. Cell Biol. 3, 93-96. doi: 10.1038/35050618

Cook, C., Gendron, T. F., Scheffel, K., Carlomagno, Y., Dunmore, J., DeTure, M., et al. (2012). Loss of HDAC6, a novel CHIP substrate, alleviates abnormal tau accumulation. Hum. Mol. Genet. 21, 2936-2945. doi: 10.1093/hmg/dds125
Crippa, V., Sau, D., Rusmini, P., Boncoraglio, A., Onesto, E., Bolzoni, E., et al. (2010). The small heat shock protein B8 (HspB8) promotes autophagic removal of misfolded proteins involved in amyotrophic lateral sclerosis (ALS). Hum. Mol. Genet. 19, 3440-3456. doi: 10.1093/hmg/ddq257

Currais, A., Hortobágyi, T., and Soriano, S. (2009). The neuronal cell cycle as a mechanism of pathogenesis in Alzheimer's disease. Aging (Albany NY) 1, 363-371. doi: 10.18632/aging.100045

Cyr, D. M., Höhfeld, J., and Patterson, C. (2002). Protein quality control: U-boxcontaining E3 ubiquitin ligases join the fold. Trends Biochem. Sci. 27, 368-375. doi: 10.1016/s0968-0004(02)02125-4

Dai, Q., Qian, S. B., Li, H. H., Mcdonough, H., Borchers, C., Huang, D., et al. (2005). Regulation of the cytoplasmic quality control protein degradation pathway by BAG2. J. Biol. Chem. 280, 38673-38681. doi: 10.1074/jbc. m507986200

Dai, Q., Zhang, C., Wu, Y., Mcdonough, H., Whaley, R. A., Godfrey, V., et al. (2003). CHIP activates HSF1 and confers protection against apoptosis and cellular stress. EMBO J. 22, 5446-5458. doi: 10.1093/emboj/cdg529

Dale, J. M., and Garcia, M. L. (2012). Neurofilament Phosphorylation during development and disease: which came first, the phosphorylation or the accumulation? J. Amino Acids 2012:382107. doi: 10.1155/2012/ 382107

Daviau, A., Proulx, R., Robitaille, K., Di Fruscio, M., Tanguay, R. M., Landry, J., et al. (2006). Down-regulation of the mixed-lineage dual leucine zipper-bearing kinase by heat shock protein 70 and its co-chaperone CHIP. J. Biol. Chem. 281, 31467-31477. doi: 10.1074/jbc.M607612200

Demand, J., Alberti, S., Patterson, C., and Höhfeld, J. (2001). Cooperation of a ubiquitin domain protein and an E3 ubiquitin ligase during chaperone/proteasome coupling. Curr. Biol. 11, 1569-1577. doi: 10. 1016/s0960-9822(01)00487-0

de Roux, N., Carel, J. C., and Léger, J. (2016). Congenital hypogonadotropic hypogonadism: a trait shared by several complex neurodevelopmental disorders. Endocr. Dev. 29, 72-86. doi: 10.1159/000438875

Dickey, C. A., Koren, J., Zhang, Y. J., Xu, Y. F., Jinwal, U. K., Birnbaum, M. J., et al. (2008). Akt and CHIP coregulate tau degradation through coordinated interactions. Proc. Natl. Acad. Sci. U S A 105, 3622-3627. doi: 10.1073/pnas. 0709180105

Dickey, C. A., Patterson, C., Dickson, D., and Petrucelli, L. (2007). Brain CHIP: removing the culprits in neurodegenerative disease. Trends Mol. Med. 13, 32-38. doi: 10.1016/j.molmed.2006.11.003

Dikshit, P., and Jana, N. R. (2007). The co-chaperone CHIP is induced in various stresses and confers protection to cells. Biochem. Biophys. Res. Commun. 357, 761-765. doi: 10.1016/j.bbrc.2007.04.018

Ding, X., and Goldberg, M. S. (2009). Regulation of LRRK2 stability by the E3 ubiquitin ligase CHIP. PLoS One 4:e5949. doi: 10.1371/journal.pone.0005949

Edkins, A. L. (2015). CHIP: a co-chaperone for degradation by the proteasome. Subcell. Biochem. 78, 219-242. doi: 10.1007/978-3-319-11731-7_11

Eldridge, A. G., and O'brien, T. (2010). Therapeutic strategies within the ubiquitin proteasome system. Cell Death Differ. 17, 4-13. doi: 10.1038/cdd.2009.82

Ellis, R. J., and Hemmingsen, S. M. (1989). Molecular chaperones: proteins essential for the biogenesis of some macromolecular structures. Trends Biochem. Sci. 14, 339-342. doi: 10.1016/0968-0004(89)90168-0

Esser, C., Scheffner, M., and Höhfeld, J. (2005). The chaperone-associated ubiquitin ligase CHIP is able to target $\mathrm{p} 53$ for proteasomal degradation. J. Biol. Chem. 280, 27443-27448. doi: 10.1074/jbc.M501574200

Fan, M., Park, A., and Nephew, K. P. (2005). CHIP (carboxyl terminus of Hsc70interacting protein) promotes basal and geldanamycin-induced degradation of estrogen receptor- $\alpha$. Mol. Endocrinol. 19, 2901-2914. doi: 10.1210/me.20050111

Faresse, N., Ruffieux-Daidie, D., Salamin, M., Gomez-Sanchez, C. E., and Staub, O. (2010). Mineralocorticoid receptor degradation is promoted by Hsp90 inhibition and the ubiquitin-protein ligase CHIP. Am. J. Physiol. Renal Physiol. 299, F1462-F1472. doi: 10.1152/ajprenal.00285.2010

Ferreira, J. V., Fôfo, H., Bejarano, E., Bento, C. F., Ramalho, J. S., Girão, H., et al. (2013). STUB1/CHIP is required for HIF1A degradation by chaperonemediated autophagy. Autophagy 9, 1349-1366. doi: 10.4161/auto.25190

Gamerdinger, M., Carra, S., and Behl, C. (2011). Emerging roles of molecular chaperones and co-chaperones in selective autophagy: focus on BAG proteins. J. Mol. Med. (Berl) 89, 1175-1182. doi: 10.1007/s00109-011-0795-6 
Gao, B., Wang, Y., Xu, W., Li, S., Li, Q., and Xiong, S. (2013). Inhibition of histone deacetylase activity suppresses IFN- $\gamma$ induction of tripartite motif 22 via CHIPmediated proteasomal degradation of IRF-1. J. Immunol. 191, 464-471. doi: 10. 4049/jimmunol.1203533

Gaude, H., Aznar, N., Delay, A., Bres, A., Buchet-Poyau, K., Caillat, C., et al. (2012). Molecular chaperone complexes with antagonizing activities regulate stability and activity of the tumor suppressor LKB1. Oncogene 31, 1582-1591. doi: 10. 1038/onc.2011.342

Gentry, M. S., Worby, C. A., and Dixon, J. E. (2005). Insights into Lafora disease: malin is an E3 ubiquitin ligase that ubiquitinates and promotes the degradation of laforin. Proc. Natl. Acad. Sci. U S A 102, 8501-8506. doi: 10.1073/pnas. 0503285102

Germano, S., Barberis, D., Santoro, M. M., Penengo, L., Citri, A., Yarden, Y., et al. (2006). Geldanamycins trigger a novel Ron degradative pathway, hampering oncogenic signaling. J. Biol. Chem. 281, 21710-21719. doi: 10. 1074/jbc.M602014200

Goldberg, A. L. (2003). Protein degradation and protection against misfolded or damaged proteins. Nature 426, 895-899. doi: 10.1038/nature02263

Graf, C., Stankiewicz, M., Nikolay, R., and Mayer, M. P. (2010). Insights into the conformational dynamics of the E3 ubiquitin ligase CHIP in complex with chaperones and E2 enzymes. Biochemistry 49, 2121-2129. doi: 10. 1021/bi901829f

Guo, D., Ying, Z., Wang, H., Chen, D., Gao, F., Ren, H., et al. (2015). Regulation of autophagic flux by CHIP. Neurosci. Bull. 31, 469-479. doi: 10.1007/s12264015-1543-7

Hartl, F. U. (1996). Molecular chaperones in cellular protein folding. Nature 381, 571-579. doi: 10.1038/381571a0

Hartl, F. U., Bracher, A., and Hayer-Hartl, M. (2011). Molecular chaperones in protein folding and proteostasis. Nature 475, 324-332. doi: 10. 1038/nature 10317

Hatakeyama, S., Matsumoto, M., Yada, M., and Nakayama, K. I. (2004). Interaction of U-box-type ubiquitin-protein ligases (E3s) with molecular chaperones. Genes Cells 9, 533-548. doi: 10.1111/j.1356-9597.2004.00742.x

Hatakeyama, S., Yada, M., Matsumoto, M., Ishida, N., and Nakayama, K. I. (2001). U box proteins as a new family of ubiquitin-protein ligases. J. Biol. Chem. 276, 33111-33120. doi: 10.1074/jbc.M102755200

Heimdal, K., Sanchez-Guixé, M., Aukrust, I., Bollerslev, J., Bruland, O., Jablonski, G. E., et al. (2014). STUB1 mutations in autosomal recessive ataxias-evidence for mutation-specific clinical heterogeneity. Orphanet J. Rare Dis. 9:146. doi: 10.1186/s13023-014-0146-0

Hershko, A. (1998). "The ubiquitin system," in Ubiquitin and the Biology of the Cell, eds J.-M. Peters, J. R. Harris and D. Finley (Boston, MA; Springer US), $1-17$.

Hirayama, S., Yamazaki, Y., Kitamura, A., Oda, Y., Morito, D., Okawa, K., et al. (2008). MKKS is a centrosome-shuttling protein degraded by disease-causing mutations via CHIP-mediated ubiquitination. Mol. Biol. Cell 19, 899-911. doi: 10.1091/mbc.E07-07-0631

Hochstrasser, M. (1996). Ubiquitin-dependent protein degradation. Annu. Rev. Genet. 30, 405-439. doi: 10.1146/annurev.genet.30.1.405

Höhfeld, J., Cyr, D. M., and Patterson, C. (2001). From the cradle to the grave: molecular chaperones that may choose between folding and degradation. EMBO Rep. 2, 885-890. doi: 10.1093/embo-reports/kve206

Hoppe, T. (2005). Multiubiquitylation by E4 enzymes: 'one size' doesn't fit all. Trends Biochem. Sci. 30, 183-187. doi: 10.1016/j.tibs.2005.02.004

Hsia, H. E., Kumar, R., Luca, R., Takeda, M., Courchet, J., Nakashima, J., et al. (2014). Ubiquitin E3 ligase Nedd4-1 acts as a downstream target of PI3K/PTEN-mTORC1 signaling to promote neurite growth. Proc. Natl. Acad. Sci. U S A 111, 13205-13210. doi: 10.1073/pnas.1400737111

Hwang, J. R., Zhang, C., and Patterson, C. (2005). C-terminus of heat shock protein 70 -interacting protein facilitates degradation of apoptosis signal-regulating kinase 1 and inhibits apoptosis signal-regulating kinase 1-dependent apoptosis. Cell Stress Chaperones 10, 147-156. doi: 10.1379/csc-90r.1

Imai, Y., Soda, M., Hatakeyama, S., Akagi, T., Hashikawa, T., Nakayama, K.-I. I., et al. (2002). CHIP is associated with parkin, a gene responsible for familial Parkinson's Disease and enhances its ubiquitin ligase activity. Mol. Cell 10, 55-67. doi: 10.1016/s1097-2765(02)00583-x

Irvine, G. B., El-Agnaf, O. M., Shankar, G. M., and Walsh, D. M. (2008). Protein aggregation in the brain: the molecular basis for Alzheimer's and Parkinson's diseases. Mol. Med. 14, 451-464. doi: 10.2119/2007-00100.Irvine
Ishigaki, S., Niwa, J. I., Yamada, S. I., Takahashi, M., Ito, T., Sone, J., et al. (2007). Dorfin-CHIP chimeric proteins potently ubiquitylate and degrade familial ALS-related mutant SOD1 proteins and reduce their cellular toxicity. Neurobiol. Dis. 25, 331-341. doi: 10.1016/j.nbd.2006.09.017

Jan, C. I., Yu, C. C., Hung, M. C., Harn, H. J., Nieh, S., Lee, H. S., et al. (2011). Tid1, CHIP and ErbB2 interactions and their prognostic implications for breast cancer patients. J. Pathol. 225, 424-437. doi: 10.1002/path.2921.

Jana, N. R., Dikshit, P., Goswami, A., Kotliarova, S., Murata, S., Tanaka, K., et al. (2005). Co-chaperone CHIP associates with expanded polyglutamine protein and promotes their degradation by proteasomes. J. Biol. Chem. 280, 11635-11640. doi: 10.1074/jbc.M412042200

Jang, K. W., Lee, K. H., Kim, S. H., Jin, T., Choi, E. Y., Jeon, H. J., et al. (2011). Ubiquitin ligase CHIP induces TRAF2 proteasomal degradation and $\mathrm{NF}-\kappa \mathrm{B}$ inactivation to regulate breast cancer cell invasion. J. Cell. Biochem. 112, 3612-3620. doi: 10.1002/jcb.23292

Jellinger, K. A. (2001). Cell death mechanisms in neurodegeneration. J. Cell. Mol. Med. 5, 1-17. doi: 10.1111/j.1582-4934.2001.tb00134.x

Jeong, J. H., An, J. Y., Kwon, Y. T., Li, L. Y., and Lee, Y. J. (2008). Quercetininduced ubiquitination and down-regulation of Her-2/neu. J. Cell. Biochem. 105, 585-595. doi: 10.1002/jcb.21859

Jiang, J., Ballinger, C. A., Wu, Y., Dai, Q., Cyr, D. M., Höhfeld, J., et al. (2001). CHIP is a U-box-dependent E3 ubiquitin Ligase: identification of Hsc70 as a Target for ubiquitylation. J. Biol. Chem. 276, 42938-42944. doi: 10.1074/jbc. M101968200

Jung, Y., Xu, W., Kim, H., Ha, N., and Neckers, L. (2007). Curcumin-induced degradation of ErbB2: a role for the E3 ubiquitin ligase CHIP and the Michael reaction acceptor activity of curcumin. Biochim. Biophys. Acta 1773, 383-390. doi: 10.1016/j.bbamcr.2006.11.004

Kalia, L. V., Kalia, S. K., Chau, H., Lozano, A. M., Hyman, B. T., and McLean, P. J. (2011). Ubiquitinylation of alpha-synuclein by carboxyl terminus Hsp70interacting protein (CHIP) is regulated by $\mathrm{Bcl}$-2-associated athanogene 5 (BAG5). PLoS One 6:e14695. doi: 10.1371/journal.pone.0014695

Kang, S. A., Cho, H. S., Yoon, J. B., Chung, I. K., and Lee, S. T. (2012). Hsp90 rescues PTK6 from proteasomal degradation in breast cancer cells. Biochem. J. 447, 313-320. doi: 10.1042/BJ20120803

Kaushik, S., and Cuervo, A. M. (2012). Chaperones in autophagy. Pharmacol. Res. 66, 484-493. doi: 10.1016/j.phrs.2012.10.002

Kettern, N., Dreiseidler, M., Tawo, R., and Höhfeld, J. (2010). Chaperone-assisted degradation: multiple paths to destruction. Biol. Chem. 391, 481-489. doi: 10 1515/BC.2010.058

Kim, C., Yun, N., Lee, J., Youdim, M. B., Ju, C., Kim, W. K., et al. (2016) Phosphorylation of CHIP at Ser 20 by Cdk5 promotes tAIF-mediated neuronal death. Cell Death Differ. 23, 333-346. doi: 10.1038/cdd.2015.103

Ko, H. S., Bailey, R., Smith, W. W., Liu, Z., Shin, J.-H., Lee, Y.-I., et al. (2009). CHIP regulates leucine-rich repeat kinase-2 ubiquitination, degradation and toxicity. Proc. Natl. Acad. Sci. U S A 106, 2897-2902. doi: 10.1073/pnas.08101 23106

Koegl, M., Hoppe, T., Schlenker, S., Ulrich, H. D., Mayer, T. U., and Jentsch, S. (1999). A novel ubiquitination factor, E4, is involved in multiubiquitin chain assembly. Cell 96, 635-644. doi: 10.1016/s0092-8674(00)80574-7

Koren, J. III, Jinwal, U. K., Lee, D. C., Jones, J. R., Shults, C. L., Johnson, A. G., et al. (2009). Chaperone signalling complexes in Alzheimer's disease. J. Cell. Mol. Med. 13, 619-630. doi: 10.1111/j.1582-4934.2008.00557.x

Korolchuk, V. I., Menzies, F. M., and Rubinsztein, D. C. (2010). Mechanisms of cross-talk between the ubiquitin-proteasome and autophagy-lysosome systems FEBS Lett. 584, 1393-1398. doi: 10.1016/j.febslet.2009.12.047

Krackhardt, A. M., Witzens, M., Harig, S., Hodi, F. S., Zauls, A. J., Chessia, M., et al. (2002). Identification of tumor-associated antigens in chronic lymphocytic leukemia by SEREX. Blood 100, 2123-2131. doi: 10.1182/blood-2002-02-0513

Krishnamoorthy, G. P., Guida, T., Alfano, L., Avilla, E., Santoro, M., Carlomagno, F., et al. (2013). Molecular mechanism of 17-allylamino-17demethoxygeldanamycin (17-AAG)-induced AXL receptor tyrosine kinase degradation. J. Biol. Chem. 288, 17481-17494. doi: 10.1074/jbc.M112.439422

Kumar, P., Ambasta, R. K., Veereshwarayya, V., Rosen, K. M., Kosik, K. S., Band, H., et al. (2007). CHIP and HSPs interact with beta-APP in a proteasomedependent manner and influence Abeta metabolism. Hum. Mol. Genet. 16, 848-864. doi: 10.1093/hmg/ddm030

Kumar, P., Pradhan, K., Karunya, R., Ambasta, R. K., and Querfurth, H. W. (2012). Cross-functional E3 ligases Parkin and C-terminus Hsp70-interacting protein 
in neurodegenerative disorders. J. Neurochem. 120, 350-370. doi: 10.1111/j. 1471-4159.2011.07588.x

Kundrat, L., and Regan, L. (2010). Identification of residues on Hsp70 and Hsp90 ubiquitinated by the cochaperone CHIP. J. Mol. Biol. 395, 587-594. doi: 10. 1016/j.jmb.2009.11.017

Lee, J. H., Khadka, P., Baek, S. H., and Chung, I. K. (2010). CHIP promotes human telomerase reverse transcriptase degradation and negatively regulates telomerase activity. J. Biol. Chem. 285, 42033-42045. doi: 10.1074/jbc.M110. 149831

Lee, J. S., Seo, T. W., Yi, J. H., Shin, K. S., and Yoo, S. J. (2013). CHIP has a protective role against oxidative stress-induced cell death through specific regulation of endonuclease G. Cell Death Dis. 4:e666. doi: 10.1038/cddis.2013. 181

Lee, J. S., and Yoo, S. J. (2013). C-terminus of Hsc70-interacting protein regulates C-terminal binding protein 2 and the expression of its target genes. Biochem. Biophys. Res. Commun. 432, 418-424. doi: 10.1016/j.bbrc.2013.01.124

Li, W., Bengtson, M. H., Ulbrich, A., Matsuda, A., Reddy, V. A., Orth, A., et al. (2008). Genome-wide and functional annotation of human E3 ubiquitin ligases identifies MULAN, a mitochondrial E3 that regulates the organelle's dynamics and signaling. PLoS One 3:e1487. doi: 10.1371/journal.pone.00 01487

Li, X., Huang, M., Zheng, H., Wang, Y., Ren, F., Shang, Y., et al. (2008). CHIP promotes Runx2 degradation and negatively regulates osteoblast differentiation. J. Cell Biol. 181, 959-972. doi: 10.1083/jcb.200 711044

Li, L., Liu, F., and Ross, A. H. (2003). PTEN regulation of neural development and CNS stem cells. J. Cell. Biochem. 88, 24-28. doi: 10.1002/jcb.10312

Li, R.-F., Shang, Y., Liu, D., Ren, Z.-S., Chang, Z., and Sui, S.-F. (2007). Differential ubiquitination of Smad1 mediated by CHIP: implications in the regulation of the bone morphogenetic protein signaling pathway. J. Mol. Biol. 374, 777-790. doi: 10.1016/j.jmb.2007.09.082

Li, F., Xie, P., Fan, Y., Zhang, H., Zheng, L., Gu, D., et al. (2009). C terminus of Hsc70-interacting protein promotes smooth muscle cell proliferation and survival through ubiquitin-mediated degradation of FoxO1. J. Biol. Chem. 284, 20090-20098. doi: 10.1074/jbc.M109.017046

Löffek, S., Wöll, S., Höhfeld, J., Leube, R. E., Has, C., Bruckner-Tuderman, L., et al. (2010). The ubiquitin ligase CHIP/STUB1 targets mutant keratins for degradation. Hum. Mutat. 31, 466-476. doi: 10.1002/humu. 21222

Luo, W., Zhong, J., Chang, R., Hu, H., Pandey, A., and Semenza, G. L. (2010). Hsp70 and CHIP selectively mediate ubiquitination and degradation of hypoxia-inducible factor (HIF)- $1 \alpha$ but not HIF-2 $\alpha$. J. Biol. Chem. 285, 3651-3663. doi: 10.1074/jbc.M109.068577

Maruyama, T., Kadowaki, H., Okamoto, N., Nagai, A., Naguro, I., Matsuzawa, A., et al. (2010). CHIP-dependent termination of MEKK2 regulates temporal ERK activation required for proper hyperosmotic response. EMBO J. 29, 2501-2514. doi: 10.1038/emboj.2010.141

McDonough, H., and Patterson, C. (2003). CHIP: a link between the chaperone and proteasome systems. Cell Stress Chaperones 8, 303-308. doi: 10.1379/14661268(2003)008<0303: calbtc > 2.0.co;2

McLaughlin, B., Buendia, M. A., Saborido, T. P., Palubinsky, A. M., Stankowski, J. N., and Stanwood, G. D. (2012). Haploinsufficiency of the E3 ubiquitin ligase C-terminus of heat shock cognate 70 interacting protein (CHIP) produces specific behavioral impairments. PLoS One 7:e36340. doi: 10. 1371/journal.pone.0036340

Meacham, G. C., Patterson, C., Zhang, W., Younger, J. M., and Cyr, D. M. (2001). The Hsc70 co-chaperone CHIP targets immature CFTR for proteasomal degradation. Nat. Cell Biol. 3, 100-105. doi: 10.1038/350 50509

Metzger, M. B., Hristova, V. A., and Weissman, A. M. (2012). HECT and RING finger families of E3 ubiquitin ligases at a glance. J. Cell Sci. 125, 531-537. doi: $10.1242 /$ jcs.091777

Miller, V. M., Nelson, R. F., Gouvion, C. M., Williams, A., Rodriguez-Lebron, E., Harper, S. Q., et al. (2005). CHIP suppresses polyglutamine aggregation and toxicity in vitro and in vivo. J. Neurosci. 25, 9152-9161. doi: 10. 1523/JNEUROSCI.3001-05.2005

Min, J.-N., Whaley, R. A., Sharpless, N. E., Lockyer, P., Portbury, A. L., and Patterson, C. (2008). CHIP deficiency decreases longevity, with accelerated aging phenotypes accompanied by altered protein quality control. Mol. Cell. Biol. 28, 4018-4025. doi: 10.1128/MCB.00296-08

Morales, J. L., and Perdew, G. H. (2007). Carboxyl terminus of hsc70-interacting protein (CHIP) can remodel mature Aryl hydrocarbon Receptor (AhR) complexes and mediate ubiquitination of both the $\mathrm{AhR}$ and the $90 \mathrm{kDa}$ heat-shock protein (hsp90) in vitro. Biochemistry 46, 610-621. doi: 10. 1021/bi062165b

Murata, S., Chiba, T., and Tanaka, K. (2003). CHIP: a quality-control E3 ligase collaborating with molecular chaperones. Int. J. Biochem. Cell Biol. 35, 572-578. doi: 10.1016/s1357-2725(02)00394-1

Murata, S., Minami, Y., Minami, M., Chiba, T., and Tanaka, K. (2001). CHIP is a chaperone-dependent E3 ligase that ubiquitylates unfolded protein. EMBO Rep. 2, 1133-1138. doi: 10.1093/embo-reports/kve246

Murata, T., and Shimotohno, K. (2006). Ubiquitination and proteasomedependent degradation of human eukaryotic translation initiation factor $4 \mathrm{E}$. J. Biol. Chem. 281, 20788-20800. doi: 10.1074/jbc.M600563200

Narayan, V., Pion, E., Landré, V., Müller, P., and Ball, K. L. (2011). Docking-dependent ubiquitination of the interferon regulatory factor-1 tumor suppressor protein by the ubiquitin ligase CHIP. J. Biol. Chem. 286, 607-619. doi: 10.1074/jbc.M110.153122

Nollen, E. A., and Morimoto, R. I. (2002). Chaperoning signaling pathways: molecular chaperones as stress-sensing 'heat shock' proteins. J. Cell Sci. 115, 2809-2816

Oh, K. H., Yang, S. W., Park, J. M., Seol, J. H., Iemura, S., Natsume, T., et al. (2011). Control of AIF-mediated cell death by antagonistic functions of CHIP ubiquitin E3 ligase and USP2 deubiquitinating enzyme. Cell Death Differ. 18, 1326-1336. doi: $10.1038 /$ cdd.2011.3

Ohi, M. D., Vander Kooi, C. W., Rosenberg, J. A., Chazin, W. J., and Gould, K. L. (2003). Structural insights into the U-box, a domain associated with multiubiquitination. Nat. Struct. Biol. 10, 250-255. doi: 10.1038/nsb906

Palubinsky, A. M., Stankowski, J. N., Kale, A. C., Codreanu, S. G., Singer, R. J., Liebler, D. C., et al. (2015). CHIP is an essential determinant of neuronal mitochondrial stress signaling. Antioxid. Redox Signal. 23, 535-549. doi: 10. 1089/ars.2014.6102

Park, C., and Cuervo, A. M. (2013). Selective autophagy: talking with the UPS. Cell Biochem. Biophys. 67, 3-13. doi: 10.1007/s12013-013-9623-7

Parsons, J. L., Tait, P. S., Finch, D., Dianova, I. I., Allinson, S. L., and Dianov, G. L. (2008). CHIP-mediated degradation and DNA damage-dependent stabilization regulate base excision repair proteins. Mol. Cell 29, 477-487. doi: 10.1016/j. molcel.2007.12.027

Passmore, L. A., and Barford, D. (2004). Getting into position: the catalytic mechanisms of protein ubiquitylation. Biochem. J. 379, 513-525. doi: 10 1042/BJ20040198

Paul, I., Ahmed, S. F., Bhowmik, A., Deb, S., and Ghosh, M. K. (2013). The ubiquitin ligase CHIP regulates c-Myc stability and transcriptional activity. Oncogene 32, 1284-1295. doi: 10.1038/onc.2012.144

Paul, I., and Ghosh, M. K. (2015). A CHIPotle in physiology and disease. Int. J. Biochem. Cell Biol. 58, 37-52. doi: 10.1016/j.biocel.2014.10.027

Peer, C. J., Sissung, T. M., and Figg, W. D. (2011). CHIP and gp78-mediated ubiquitination of CYP3A4: implications for the pharmacology of anticancer agents. Cancer Biol. Ther. 11, 549-551. doi: 10.4161/cbt.11.6.14834

Peng, H.-M. M., Morishima, Y., Jenkins, G. J., Dunbar, A. Y., Lau, M., Patterson, C., et al. (2004). Ubiquitylation of neuronal nitric-oxide synthase by CHIP, a chaperone-dependent E3 ligase. J. Biol. Chem. 279, 52970-52977. doi: 10.1074/jbc.M406926200

Petrucelli, L., Dickson, D., Kehoe, K., Taylor, J., Snyder, H., Grover, A., et al. (2004). CHIP and Hsp70 regulate tau ubiquitination, degradation and aggregation. Hum. Mol. Genet. 13, 703-714. doi: 10.1093/hmg/ ddh083

Pickart, C. M. (2001). Mechanisms underlying ubiquitination. Annu. Rev. Biochem. 70, 503-533. doi: 10.1146/annurev.biochem.70.1.503

Pratt, W. B., Gestwicki, J. E., Osawa, Y., and Lieberman, A. P. (2015). Targeting Hsp90/Hsp70-based protein quality control for treatment of adult onset neurodegenerative diseases. Annu. Rev. Pharmacol. Toxicol. 55, 353-371. doi: 10.1146/annurev-pharmtox-010814-124332

Qian, S.-B., McDonough, H., Boellmann, F., Cyr, D. M., and Patterson, C. (2006). CHIP-mediated stress recovery by sequential ubiquitination of substrates and Hsp70. Nature 440, 551-555. doi: 10.1038/nature04600 
Rao, S. N., Sharma, J., Maity, R., and Jana, N. R. (2010). Co-chaperone CHIP stabilizes aggregate-prone malin, a ubiquitin ligase mutated in Lafora disease. J. Biol. Chem. 285, 1404-1413. doi: 10.1074/jbc.M109.006312

Ronnebaum, S. M., Patterson, C., and Schisler, J. C. (2014). Emerging evidence of coding mutations in the ubiquitin-proteasome system associated with cerebellar ataxias. Hum. Genome Var. 1:14018. doi: 10.1038/hgv.2014.18

Ronnebaum, S. M., Wu, Y., McDonough, H., and Patterson, C. (2013). The ubiquitin ligase CHIP prevents SirT6 degradation through noncanonical ubiquitination. Mol. Cell. Biol. 33, 4461-4472. doi: 10.1128/MCB.00480-13

Sarkar, S., Brautigan, D. L., Parsons, S. J., and Larner, J. M. (2014). Androgen receptor degradation by the E3 ligase CHIP modulates mitotic arrest in prostate cancer cells. Oncogene 33, 26-33. doi: 10.1038/onc.2012.561

Scaglione, K. M., Zavodszky, E., Todi, S. V., Patury, S., Xu, P., RodríguezLebrón, E., et al. (2011). Ube2w and ataxin-3 coordinately regulate the ubiquitin ligase CHIP. Mol. Cell 43, 599-612. doi: 10.1016/j.molcel.2011.05.036

Schulman, B. A., and Chen, Z. J. (2005). Protein ubiquitination: CHIPping away the symmetry. Mol. Cell 20, 653-655. doi: 10.1016/j.molcel.2005.11.019

Schulz, R., Dobbelstein, M., and Moll, U. M. (2012). HSP90 inhibitor antagonizing MIF: the specifics of pleiotropic cancer drug candidates. Oncoimmunology 1, 1425-1426. doi: 10.4161/onci.21173

Sedek, M., van der Velden, L. M., and Strous, G. J. (2014). Multimeric growth hormone receptor complexes serve as signaling platforms. J. Biol. Chem. 289, 65-73. doi: 10.1074/jbc.M113.523373

Seglen, P. O., and Bohley, P. (1992). Autophagy and other vacuolar protein degradation mechanisms. Experientia 48, 158-172. doi: 10.1007/bf01923509

Sengupta, S., Badhwar, I., Upadhyay, M., Singh, S., and Ganesh, S. (2011). Malin and laforin are essential components of a protein complex that protects cells from thermal stress. J. Cell Sci. 124, 2277-2286. doi: 10.1242/jcs.082800

Shang, Y., Xu, X., Duan, X., Guo, J., Wang, Y., Ren, F., et al. (2014). Hsp70 and Hsp90 oppositely regulate TGF- $\beta$ signaling through CHIP/Stub1. Biochem. Biophys. Res. Commun. 446, 387-392. doi: 10.1016/j.bbrc.2014.02.124

Shang, Y., Zhao, X., Xu, X., Xin, H., Li, X., Zhai, Y., et al. (2009). CHIP functions an E3 ubiquitin ligase of Runx1. Biochem. Biophys. Res. Commun. 386, 242-246. doi: 10.1016/j.bbrc.2009.06.043

Shen, M., Schmitt, S., Buac, D., and Dou, Q. P. (2013). Targeting the ubiquitinproteasome system for cancer therapy. Expert Opin. Ther. Targets 17, 1091-1108. doi: 10.1517/14728222.2013.815728

Shi, C. H., Schisler, J. C., Rubel, C. E., Tan, S., Song, B., McDonough, H., et al. (2014). Ataxia and hypogonadism caused by the loss of ubiquitin ligase activity of the U box protein CHIP. Hum. Mol. Genet. 23, 1013-1024. doi: 10. 1093/hmg/ddt497

Shi, Y., Wang, J., Li, J. D., Ren, H., Guan, W., He, M., et al. (2013). Identification of CHIP as a novel causative gene for autosomal recessive cerebellar ataxia. PLoS One 8:e81884. doi: 10.1371/journal.pone.0081884

Shimura, H., Schwartz, D., Gygi, S. P., and Kosik, K. S. (2004). CHIP-Hsc70 complex ubiquitinates phosphorylated tau and enhances cell survival. J. Biol. Chem. 279, 4869-4876. doi: 10.1074/jbc.m305838200

Shin, Y., Klucken, J., Patterson, C., Hyman, B. T., and McLean, P. J. (2005). The co-chaperone carboxyl terminus of Hsp70-interacting protein (CHIP) mediates alpha-synuclein degradation decisions between proteasomal and lysosomal pathways. J. Biol. Chem. 280, 23727-23734. doi: 10.1074/jbc.M5033 26200

Sievers, F., Wilm, A., Dineen, D., Gibson, T. J., Karplus, K., Li, W., et al. (2011). Fast, scalable generation of high-quality protein multiple sequence alignments using Clustal Omega. Mol. Syst. Biol. 7:539. doi: 10.1038/msb.2011.75

Slotman, J. A., da Silva Almeida, A. C., Hassink, G. C., van de Ven, R. H. A., van Kerkhof, P., Kuiken, H. J., et al. (2012). Ubc13 and COOH terminus of Hsp70-interacting protein (CHIP) are required for growth hormone receptor endocytosis. J. Biol. Chem. 287, 15533-15543. doi: 10.1074/jbc.M111.302521

Sobol, R. W. (2008). CHIPping away at base excision repair. Mol. Cell 29, 413-415. doi: 10.1016/j.molcel.2008.02.004

Soss, S. E., Rose, K. L., Hill, S., Jouan, S., and Chazin, W. J. (2015). Biochemical and proteomic analysis of ubiquitination of $\mathrm{Hsc70}$ and Hsp70 by the E3 ligase CHIP. PLoS One 10:e0128240. doi: 10.1371/journal.pone.0128240

Soss, S. E., Yue, Y., Dhe-Paganon, S., and Chazin, W. J. (2011). E2 conjugating enzyme selectivity and requirements for function of the E3 ubiquitin ligase CHIP. J. Biol. Chem. 286, 21277-21286. doi: 10.1074/jbc.M111.224006

Su, L., Zhang, Y., Zhang, C. Y., Zhang, A. L., Mei, X. L., Zhao, Z. J., et al. (2013). Genetic screening for mutations in the chip gene in intracranial aneurysm patients of Chinese Han nationality. Asian Pac. J. Cancer Prev. 14, 1687-1689. doi: 10.7314/apjcp.2013.14.3.1687

Sun, X., Fratz, S., Sharma, S., Hou, Y., Rafikov, R., Kumar, S., et al. (2011). C-terminus of heat shock protein 70-interacting protein-dependent GTP cyclohydrolase I degradation in lambs with increased pulmonary blood flow. Am. J. Respir. Cell Mol. Biol. 45, 163-171. doi: 10.1165/rcmb.2009-0467OC

Sun, C., Li, H. L., Shi, M. L., Liu, Q. H., Bai, J., and Zheng, J. N. (2014). Diverse roles of C-terminal Hsp70-interacting protein (CHIP) in tumorigenesis. J. Cancer Res. Clin. Oncol. 140, 189-197. doi: 10.1007/s00432-013-1571-5

Tatham, M. H., Plechanovová, A., Jaffray, E. G., Salmen, H., and Hay, R. T. (2013). Ube2W conjugates ubiquitin to alpha-amino groups of protein N-termini. Biochem. J. 453, 137-145. doi: 10.1042/BJ20130244

Teng, Y., Rezvani, K., and De Biasi, M. (2015). UBXN2A regulates nicotinic receptor degradation by modulating the E3 ligase activity of CHIP. Biochem. Pharmacol. 97, 518-530. doi: 10.1016/j.bcp.2015.08.084

Tetzlaff, J. E., Putcha, P., Outeiro, T. F., Ivanov, A., Berezovska, O., Hyman, B. T., et al. (2008). CHIP targets toxic $\beta$-synuclein oligomers for degradation. J. Biol. Chem. 283, 17962-17968. doi: 10.1074/jbc.M802283200

Theodoraki, M. A., and Caplan, A. J. (2012). Quality control and fate determination of Hsp90 client proteins. Biochim. Biophys. Acta 1823, 683-688. doi: 10.1016/j.bbamcr.2011.08.006

Tsou, W. L., Burr, A. A., Ouyang, M., Blount, J. R., Scaglione, K. M., and Todi, S. V. (2013). Ubiquitination regulates the neuroprotective function of the deubiquitinase ataxin-3 in vivo. J. Biol. Chem. 288, 34460-34469. doi: 10. 1074/jbc.M113.513903

Tsukahara, F., and Maru, Y. (2010). Bag1 directly routes immature BCR-ABL for proteasomal degradation. Blood 116, 3582-3592. doi: 10.1182/blood-2009-10249623

Tsvetkov, P., Adamovich, Y., Elliott, E., and Shaul, Y. (2011). E3 ligase STUB1/CHIP regulates $\mathrm{NAD}(\mathrm{P}) \mathrm{H}$ :quinone oxidoreductase 1 (NQO1) accumulation in aged brain, a process impaired in certain Alzheimer disease patients. J. Biol. Chem. 286, 8839-8845. doi: 10.1074/jbc.M110. 193276

Upadhyay, A., Amanullah, A., Chhangani, D., Mishra, R., and Mishra, A. (2015). Selective multifaceted E3 ubiquitin ligases barricade extreme defense: potential therapeutic targets for neurodegeneration and ageing. Ageing Res. Rev. 24, 138-159. doi: 10.1016/j.arr.2015.07.009

Urushitani, M., Kurisu, J., Tateno, M., Hatakeyama, S., Nakayama, K., Kato, S., et al. (2004). CHIP promotes proteasomal degradation of familial ALS-linked mutant SOD1 by ubiquitinating Hsp/Hsc70. J. Neurochem. 90, 231-244. doi: 10. 1111/j.1471-4159.2004.02486.x

Uversky, V. N., and Fink, A. (2007). Protein Misfolding, Aggregation and Conformational Diseases: Part B: Molecular Mechanisms of Conformational Diseases. Berlin: Springer Science and Business Media.

Wang, X., and DeFranco, D. B. (2005). Alternative effects of the ubiquitinproteasome pathway on glucocorticoid receptor down-regulation and transactivation are mediated by CHIP, an E3 ligase. Mol. Endocrinol. 19, 1474-1482. doi: 10.1210/me.2004-0383

Wang, Y., Guan, S., Acharya, P., Liu, Y., Thirumaran, R. K., Brandman, R., et al. (2012). Multisite phosphorylation of human liver cytochrome P450 3A4 enhances its gp78-and CHIP-mediated ubiquitination: a pivotal role of its SER-478 residue in the gp78-catalyzed reaction. Mol. Cell. Proteomics 11:M111.010132. doi: 10.1074/mcp.M111.010132

Wang, S., Li, Y., Hu, Y. H., Song, R., Gao, Y., Liu, H. Y., et al. (2013a). STUB1 is essential for T-cell activation by ubiquitinating CARMA1. Eur. J. Immunol. 43, 1034-1041. doi: 10.1002/eji.201242554

Wang, S., Wu, X., Zhang, J., Chen, Y., Xu, J., Xia, X., et al. (2013b). CHIP functions as a novel suppressor of tumour angiogenesis with prognostic significance in human gastric cancer. Gut 62, 496-508. doi: 10.1136/gutjnl-2011-301522

Wang, Y., and Mandelkow, E. (2012). Degradation of tau protein by autophagy and proteasomal pathways. Biochem. Soc. Trans. 40, 644-652. doi: 10 1042/BST20120071

Wang, Q., Song, F., Zhang, C., Zhao, X., Zhu, Z., Yu, S., et al. (2011). Carboxylterminus of Hsc70 interacting protein mediates 2,5-hexanedione-induced neurofilament medium chain degradation. Biochem. Pharmacol. 81, 793-799. doi: 10.1016/j.bcp.2010.12.021

Wang, J., Zhao, Q., Qi, Q., Gu, H. Y., Rong, J. J., Mu, R., et al. (2011). Gambogic acid-induced degradation of mutant $\mathrm{p} 53$ is mediated by proteasome and related to CHIP. J. Cell. Biochem. 112, 509-519. doi: 10.1002/jcb.22941 
Weathington, N. M., and Mallampalli, R. K. (2014). Emerging therapies targeting the ubiquitin proteasome system in cancer. J. Clin. Invest. 124, 6-12. doi: 10. 1172/JCI71602

Wei, Q., Sha, Y., Bhattacharya, A., Abdel Fattah, E., Bonilla, D., Jyothula, S. S., et al. (2014). Regulation of IL-4 receptor signaling by STUB1 in lung inflammation. Am. J. Respir. Crit. Care Med. 189, 16-29. doi: 10.1164/rccm.2013050874OC

Wen, J., Luo, K. J., Hu, Y., Yang, H., and Fu, J. H. (2013). Metastatic lymph node CHIP expression is a potential prognostic marker for resected esophageal squamous cell carcinoma patients. Ann. Surg. Oncol. 20, 1668-1675. doi: 10. 1245/s10434-012-2733-4

Williams, A. J., Knutson, T. M., Colomer Gould, V. F., and Paulson, H. L. (2009). In vivo suppression of polyglutamine neurotoxicity by C-terminus of Hsp70interacting protein (CHIP) supports an aggregation model of pathogenesis. Neurobiol. Dis. 33, 342-353. doi: 10.1016/j.nbd.2008.10.016

Willis, M. S., Schisler, J. C., and Patterson, C. (2008). Appetite for destruction: E3 ubiquitin-ligase protection in cardiac disease. Future Cardiol. 4, 65-75. doi: 10. 2217/14796678.4.1.65

Windheim, M., Peggie, M., and Cohen, P. (2008). Two different classes of E2 ubiquitin-conjugating enzymes are required for the mono-ubiquitination of proteins and elongation by polyubiquitin chains with a specific topology. Biochem. J. 409, 723-729. doi: 10.1042/bj20071338

Woo, C.-H., Le, N.-T., Shishido, T., Chang, E., Lee, H., Heo, K.-S., et al. (2010). Novel role of $\mathrm{C}$ terminus of $\mathrm{Hsc} 70$-interacting protein (CHIP) ubiquitin ligase on inhibiting cardiac apoptosis and dysfunction via regulating ERK5-mediated degradation of inducible cAMP early repressor. FASEB J. 24, 4917-4928. doi: 10.1096/fj.10-162636

Xia, T., Dimitropoulou, C., Zeng, J., Antonova, G. N., Snead, C., Venema, R. C., et al. (2007). Chaperone-dependent E3 ligase CHIP ubiquitinates and mediates proteasomal degradation of soluble guanylyl cyclase. Am. J. Physiol. Heart Circ. Physiol. 293, H3080-H3087. doi: 10.1152/ajpheart.005 79.2007

Xie, P., Fan, Y., Zhang, H., Zhang, Y., She, M., Gu, D., et al. (2009). CHIP represses myocardin-induced smooth muscle cell differentiation via ubiquitin-mediated proteasomal degradation. Mol. Cell. Biol. 29, 2398-2408. doi: 10.1128/MCB. 01737-08

Xu, Z., Kohli, E., Devlin, K. I., Bold, M., Nix, J. C., and Misra, S. (2008). Interactions between the quality control ubiquitin ligase CHIP and ubiquitin conjugating enzymes. BMC Struct. Biol. 8, 26-26. doi: 10.1186/1472-6807-8-26

Xu, W., Marcu, M., Yuan, X., Mimnaugh, E., Patterson, C., and Neckers, L. (2002). Chaperone-dependent E3 ubiquitin ligase CHIP mediates a degradative pathway for c-ErbB2/Neu. Proc. Natl. Acad. Sci. US A 99, 12847-12852. doi: 10. 1073/pnas.202365899

Yaguchi, H., Ohkura, N., Takahashi, M., Nagamura, Y., Kitabayashi, I., and Tsukada, T. (2004). Menin missense mutants associated with multiple endocrine neoplasia type 1 are rapidly degraded via the ubiquitin-proteasome pathway. Mol. Cell. Biol. 24, 6569-6580. doi: 10.1128/mcb.24.15.6569-6580. 2004

Yan, S., Sun, X., Xiang, B., Cang, H., Kang, X., Chen, Y., et al. (2010). Redox regulation of the stability of the SUMO protease SENP3 via interactions with CHIP and Hsp90. EMBO J. 29, 3773-3786. doi: 10.1038/emboj.2010.245
Yang, S. W., Oh, K. H., Park, E., Chang, H. M., Park, J. M., Seong, M. W., et al. (2013). USP47 and C terminus of Hsp70-interacting protein (CHIP) antagonistically regulate katanin-p60-mediated axonal growth. J. Neurosci. 33, 12728-12738. doi: 10.1523/JNEUROSCI.0698-13.2013

Yang, M., Wang, C., Zhu, X., Tang, S., Shi, L., Cao, X., et al. (2011). E3 ubiquitin ligase CHIP facilitates Toll-like receptor signaling by recruiting and polyubiquitinating Src and atypical PKCzeta. J. Exp. Med. 208, 2099-2112. doi: 10.1084/jem.20102667

Yerbury, J. J., Ooi, L., Dillin, A., Saunders, D. N., Hatters, D. M., Beart, P. M., et al. (2016). Walking the tightrope: proteostasis and neurodegenerative disease. J. Neurochem. 137, 489-505. doi: 10.1111/jnc.13575

Zhang, Q. G., Han, D., Wang, R. M., Dong, Y., Yang, F., Vadlamudi, R. K., et al. (2011). C terminus of Hsc70-interacting protein (CHIP)-mediated degradation of hippocampal estrogen receptor- $\alpha$ and the critical period hypothesis of estrogen neuroprotection. Proc. Natl. Acad. Sci. US A 108, E617-E624. doi: 10. 1073/pnas.1104391108

Zhang, W., Liu, Z., Bao, X., Qin, Y., Taylor, A., and Shang, F. (2015). CHIP knockdown reduced heat shock response and protein quality control capacity in lens epithelial cells. Curr. Mol. Med. 15, 652-662. doi: 10 2174/1566524015666150831131636

Zhang, M., Windheim, M., Roe, S. M., Peggie, M., Cohen, P., Prodromou, C., et al. (2005). Chaperoned ubiquitylation-crystal structures of the CHIP U box E3 ubiquitin ligase and a CHIP-Ubc13-Uevla complex. Mol. Cell 20, 525-538. doi: 10.1016/j.molcel.2005.09.023

Zhang, H. T., Zeng, L. F., He, Q. Y., Tao, W. A., Zha, Z. G., and Hu, C. D. (2016). The E3 ubiquitin ligase CHIP mediates ubiquitination and proteasomal degradation of PRMT5. Biochim. Biophys. Acta 1863, 335-346. doi: 10.1016/j. bbamcr.2015.12.001

Zhao, B., Sun, G., Feng, G., Duan, W., Zhu, X., Chen, S., et al. (2012). Carboxy terminus of heat shock protein (HSP) 70-interacting protein (CHIP) inhibits HSP70 in the heart. J. Physiol. Biochem. 68, 485-491. doi: 10.1007/s13105-0120161-3

Zhou, P., Fernandes, N., Dodge, I. L., Lakku Reddi, A., Rao, N., Safran, H., et al. (2003). ErbB2 degradation mediated by the co-chaperone protein CHIP. J. Biol. Chem. 278, 13829-13837. doi: 10.1074/jbc.M209640200

Zhu, X., Zhang, J., Sun, H., Jiang, C., Dong, Y., Shan, Q., et al. (2014). Ubiquitination of inositol-requiring enzyme 1 (IRE1) by the E3 ligase CHIP mediates the IRE1/TRAF2/JNK pathway. J. Biol. Chem. 289, 30567-30577. doi: $10.1074 /$ jbc.M114.562868

Conflict of Interest Statement: The authors declare that the research was conducted in the absence of any commercial or financial relationships that could be construed as a potential conflict of interest.

Copyright (c) 2016 Joshi, Amanullah, Upadhyay, Mishra, Kumar and Mishra. This is an open-access article distributed under the terms of the Creative Commons Attribution License (CC BY). The use, distribution and reproduction in other forums is permitted, provided the original author(s) or licensor are credited and that the original publication in this journal is cited, in accordance with accepted academic practice. No use, distribution or reproduction is permitted which does not comply with these terms. 